\title{
Market Familiarity and the Location of South and North MNEs
}

\author{
Celine Azemar* Julia Darby ${ }^{\dagger} \quad$ Rodolphe Desbordes ${ }^{\ddagger} \quad$ Ian Wooton $^{\S}$
}

\begin{abstract}
We use a systematic empirical analysis of the determinants of South-South (SS) and North-South (NS) foreign direct investment (FDI) as a canvas to explore how multinational enterprises' (MNEs) location decisions are shaped by better acquaintance with a foreign market resulting from bilateral ties, experience of international expansion, and knowledge of how to deal with poor governance. We find that these various aspects of market familiarity, which can interact together, are important to explain and differentiate the location behaviours of South MNEs (S-MNEs) and North MNEs (N-MNEs) in developing countries.
\end{abstract}

JEL classification: F22. Keywords: South-South FDI; governance; institutions; familiarity; distance.

\footnotetext{
${ }^{*}$ University of Glasgow. Email: Celine.Azemar@glasgow.ac.uk

${ }^{\dagger}$ University of Strathclyde. Email: julia.darby@strath.ac.uk

${ }^{\ddagger}$ Corresponding author. Address: Department of Economics, Sir William Duncan Building, University of Strathclyde, 130 Rottenrow, Glasgow G4 0GE, Scotland, United Kingdom. Telephone/Fax number: (+44) (0)141 548 3961/4445. E-mail: rodolphe.desbordes@ strath.ac.uk

$\S$ University of Strathclyde and CEPR. Email: ian.wooton@strath.ac.uk
} 


\title{
1 Introduction
}

\author{
Country-specific research was extremely useful in providing data and ideas for the research that attempted to draw broader generaliza- \\ tions about the multinationalization of firms from the developing world. Without the broader work, however, I am afraid that we would \\ remain lost in the specific details of individual countries. It remains important to go beyond country studies to look for general patterns, \\ although those patterns may be contingent on country characteristics (Wells, 2009).
}

In the last decade, the world has experienced a dramatic increase in outward foreign direct investment (FDI) from developing ('South') countries. The latest World Investment Report (UNCTAD, 2010) reports that South FDI represents now about one-quarter of total outward flows, a substantial increase relative to the $3 \%$ figure of the early eighties. This second wave of outward South FDI has triggered renewed interest in the idiosyncratic characteristics of South multinational enterprises (S-MNEs). ${ }^{1}$ While some scholars have been interested in understanding how a South firm could invest in a more advanced developed ('North') country despite having no obvious firm-specific advantages (FSAs), most attention has been devoted to South-South FDI (SS-FDI) flows.

SS-FDI flows account for the bulk of outward South FDI (Goldstein, 2009). According to some estimates, they also represent one third to one half of total FDI inflows reported by developing countries (Aykut and Ratha, 2004; UNCTAD, 2006). In the context of limited empirical evidence, mainly drawn from selective firm and country case studies, e.g. Lall (1983) or Goldstein (2009), researchers stress the importance of "market familiarity" in shaping the decisions of S-MNEs. Market familiarity is also referred to as 'psychic' or 'institutional' distance and is a multifaceted concept in this literature, with different implications for investment in the South by S-MNEs and North MNEs (N-MNEs), depending on the perspective that is adopted. In this paper, we aim to characterise and identify the implications of market familiarity as they apply through three distinct mechanisms: the evolution stage hypothesis, the resilience advantage hypothesis, the mitigating role of bilateral ties hypothesis. We introduce each of these concepts in turn.

The evolution stage hypothesis. Some elements of market familiarity emphasised in the literature are likely to be of greatest importance to relatively immature MNEs, that is those in the formative stages of their international expansion. In this sense, the heavy presence of S-MNEs in neighbouring developing countries is perceived as the natural outcome of an incremental process of international expansion. S-MNEs lacking international experience ${ }^{2}$ first invest in countries with

\footnotetext{
${ }^{1}$ The first wave of outward South FDI took place in the late seventies/early eighties. It was interrupted by the debt crises which struck the leading source of FDI, Latin America (Ramamurti and Singh, 2009).

${ }^{2}$ Lack of international experience does not necessarily mean that these firms are young. Indeed, the company studies provided in the volumes of Goldstein (2009) and Ramamurti and Singh (2009) suggest that prominent S-MNEs had operated in their home countries for decades before investing abroad. However anecdotal evidence and outward FDI flows by South countries indicate that international expansion of South firms only became a general trend in the late nineties/early noughties. This global lack of international experience explains why S-MNEs are qualified in Ramamurti and Singh (2009) as 'infant' MNEs, in contrast to the 'mature' N-MNEs.
} 
which they are relatively familiar, such as those characterised by strong bilateral ties (e.g. physical proximity, common language) with their home countries. In doing so, they seek to limit difficulties associated with operating in a foreign business environment. N-MNEs will also face costs associated with their 'liability of foreignness' (Zaheer, 1995), but their greater experience of engaging in FDI may mitigate these costs and therefore their location choices are less likely to be sensitive to the existence of bilateral ties between their source country and the destination countries that they target.

The resilience advantage hypothesis. Given the importance that the FDI literature attaches to good public governance ${ }^{3}$ and the apparent willingness of S-MNEs to minimise the costs of doing business abroad, it is somehow surprising that recent research on SS-FDI (Cuervo-Cazurra, 2006; Cuervo-Cazurra and Genc, 2008) has echoed arguments already made in the late seventies/early eighties by Lecraw (1977) or Kumar (1982) about the relative insensitivity of S-MNEs to poor institutional quality in their location choices. The premise is that the expansion of S-MNEs has been less hindered by poor governance conditions abroad because they have developed extensive familiarity in coping with such conditions at home, giving them a resilience advantage. By comparison, N-MNEs have not had the same incentives to learn how to be resilient to adverse governance conditions. They are therefore less likely to be present in environments that require the exploitation of a resilience advantage. Hence, while the lack of familiarity with international expansion may put S-MNEs at a slight disadvantage relative to the more mature N-MNEs when investing in distant South countries, their home-grown experience of operating in unfavourable business environments ought to give them an offsetting competitive edge over their North counterparts, especially in risky developing countries.

The mitigating role of bilateral ties. As postulated in the evolution stage hypothesis the location of S-MNEs and NMNEs is likely to be positively influenced by the reduction in information and transaction costs provided by bilateral ties, in the shape of a common language, a colonial relationship or migrant networks. In addition, it has also been hypothesised, especially in the context of Chinese and Indian outward FDI, that some of the benefits of market familiarity may be accessed or created through the interaction of bilateral ties with governance conditions (Wells, 1983). The underlying idea is that bilateral ties, in addition to other benefits, can alleviate the difficulties generated by poor governance and even provide alternative informal institutions more supportive of productive activities, e.g. migrant communities can threaten collective punishment of cheaters (Rauch, 2001). Overall, bilateral ties can not only influence the location of S-MNEs and N-MNEs by increasing their familiarity with a given foreign country, an effect that should be weaker for the more internationally experienced N-MNEs, but also by mitigating indistinctively for both S-MNEs and N-MNEs the impact of

\footnotetext{
${ }^{3}$ Wei (2000), Daude and Stein (2007) and Azémar and Desbordes (2009) find a strong statistical and substantial positive impact of good public governance on FDI.
} 
destination governance.

Overall, the combination and interaction of these three elements of market familiarity (lack of international experience, knowledge of how to deal with poor governance, bilateral ties) may explain both why S-MNEs invest in the South and account for the relatively large share held by SS-FDI in the total FDI flows received by the South. In other words, market familiarity, in its different variations, appear to play a key role in shaping and differentiating the location behaviour of S-MNEs and N-MNEs.

A key objective of our paper is to explore these aspects of market familiarity and their interactions empirically, through a systematic comparative analysis of the determinants of SS-FDI and North-South FDI (NS-FDI), based on the unprecedented exploitation of a large bilateral FDI database on South FDI. Our contribution to the current literature is three-fold. First, as Wells (2009) points out, there is little and inconclusive empirical evidence about how the behaviour of S-MNEs truly differs from that of N-MNEs. Second, while we do not claim to be the first study to investigate the specific issue of the relative sensitivity of S-MNEs and N-MNEs to governance conditions, we believe that we tackle this question in a more coherent, convincing, and robust manner than previous research, both from a conceptual and econometric perspective. Third, we provide a deeper examination of a range of bilateral ties that can shape the location decisions of MNEs, including the role of these ties in reducing the costs of doing business in foreign countries characterised by poor governance.

We find that the coarse picture of S-MNEs that can be gathered from anecdotal evidence and case studies is in agreement with the general patterns that we detect in our broad cross-country investigation. S-MNEs tend to invest more in physically and linguistically close destination countries than N-MNEs, but are much much more likely than the latter to originate from, and invest in, countries characterised by poor macroeconomic and governance conditions. We show robustly that S-MNEs' superior resilience to bad governance abroad comes from their resilience advantage, that is their ability to leverage their home experience of dealing with similar institutional difficulties.

Bilateral ties and international institutions are also shown to be important. In addition to reproducing the common results that physical proximity and a shared common language positively influence bilateral FDI, we also highlight the importance of bilateral trust, proxied by religious similarity, and the role of migrant networks. The latter have different impacts on FDI depending on their 'direction'. We also distinguish bilateral regional trade agreements (RTAs), ${ }^{4}$ from multilateral RTAs, and investigate their separate effects on intra-regional and extra-regional FDI. We find that only multilateral

\footnotetext{
${ }^{4}$ RTAs are also called Preferential Trade Agreements.
} 
RTAs influence FDI; the intra-regional type for SS-FDI and the extra-regional type for NS-FDI.

Some bilateral ties also appear to confer reduced information and transaction costs associated with operating in a foreign business environment to all MNEs via their interaction with governance conditions. A common language seems to be particularly important when dealing with an inefficient government or red tape. On the other hand, migrant networks do not seem to alleviate the institutional constraints that a MNE may face. Finally, we obtain some tentative evidence about the other firm-specific advantages that S-MNEs are likely to have, in addition to their resilience advantage. S-MNEs do not seem to be any less technologically advanced than N-MNEs.

The rest of the paper is structured as follows. Section 2 provides a brief literature review, structured around three main research questions: the evolution stage hypothesis, the resilience advantage hypothesis and the mitigating role of bilateral ties hypothesis. Section 3 presents our empirical strategy that we adopt to test these three hypotheses. Section 4 describes the data and estimation method used. Section 5 reports and discusses our empirical results. Section 6 concludes.

\section{Literature review and research questions}

The evolution stage hypothesis

Existing research on S-MNEs mainly consists of country-case studies. Early research on 'Third World' MNEs was conducted by Lall (1983) and Wells (1983), while the volumes of Goldstein (2009) and Ramamurti and Singh (2009) mark the renewed interest in now called 'Emerging' MNEs. In three decades, the typical picture painted of S-MNEs has not changed much. They are still typically perceived to be at an early stage of their internationalisation, and as such are assumed to be enticed to invest in countries where the costs arising from their lack of familiarity with the environment are minimised, as suggested for instance by the behavourial theory of the Uppsala School (Johanson and Vahlne, 1977). This liability of foreignness (Zaheer, 1995) can be reduced by encouraging flows of information and thereby reducing 'psychic distance'. Factors important in this regard include physical proximity, common language, shared history or migrant networks (Brewer, 2007). Hence, S-MNEs are expected, and indeed frequently observed, to locate in destination countries which have strong bilateral ties with their source country (Aykut and Ratha, 2004; UNCTAD, 2006). In contrast, N-MNEs are generally assumed to be more mature MNEs, which have accumulated the internationalisation knowledge necessary to be present in more distant countries (Ramamurti and Singh, 2009). They are expected to remain sensitive to bilateral ties, but to a lower degree than S-MNEs. 
Some limited econometric evidence suggesting that South and N-MNEs may be at different stages of their evolution can be found in Gao (2005), which reports that firms from Asian developing economies (Singapore, Taiwan, Malaysia, and Thailand) tend to invest in more physically proximate countries than do OECD source countries. Unfortunately, the coverage of South source countries considered in this study is very narrow and it is unclear whether Singapore and Taiwan can truly be classified as developing countries. In addition, the Tobit model used is not appropriate for dealing with zero values present in the data (Santos and Tenreyro, 2006). More worryingly for the evolution stage hypothesis are the results of Tong (2005). Using a larger sample of source developing countries, she finds that market familiarity (in the form of physical proximity, common language, ethnic Chinese networks) matters more for foreign investors located in developed countries. Overall, the empirical validity of the evolution stage hypothesis appears questionable.

\section{The resilience advantage hypothesis}

Given that S-MNEs appear only to be at the beginning of the internationalisation of their activities, with an associated preference for familiar destination countries, it is somehow paradoxical that the literature has repeatedly stressed their willingness and ability to operate in countries characterised by poor governance, that is to say in locations where the business conditions are difficult and the operating costs are likely to be large. ${ }^{5}$ In other words, their location strategy does not always appear to be in line with the cost minimisation strategy that would be expected from MNEs in their infancy. The obvious solution to this conundrum is that S-MNEs feel confident that they will be able to operate in such challenging environments because they have accumulated experiential knowledge about how to deal with institutional deficiencies (voids) in their home country, prior to their internationalisation. In other words, they are familiar with bad governance, they have successfully overcome the difficulties that the latter generates, and this home country experience is likely to be part of their firm-specific advantages (FSAs) when expanding abroad. On the other hand, N-MNEs have not had the opportunity to be exposed to poor institutional quality at home and therefore, in the absence of the relevant managerial expertise, are much less likely to invest in risky country. An analytical model exemplifying this reasoning can be found in Darby, Desbordes, and Wooton (2010). This paper builds upon the idea that expected returns on investments in the South may be reduced due to a higher risk of a bad institutional environment. However, the subjective probability that MNEs attach to institutional risk, such as expropriation, depends on their experience of dealing with a bad institutional

\footnotetext{
${ }^{5}$ For instance Lall (1983) writes, p.63 "There is a general impression in the relevant literature that Third World MNCs have particular skills in setting up operations in difficult, unindustrialised environments. The skills range from negotiation bureaucratic barriers (and perhaps giving 'kickbacks'), setting up basic infrastructural facilities, managing with restricted inputs and living in very rough conditions to locating new local suppliers, adapting the product to local (simple, low-price) needs and imparting essential skills to local labour". Twenty years later, a similar diagnostic is made by Khanna and Palepu (2010), who discuss how emerging MNEs can cope better with institutional voids than their more advanced counterparts. See also Dixit (2009).
} 
environment at home. Investors from countries that have experienced poor domestic institutional quality are less deterred by country risk abroad. Two empirical studies support this line of reasoning.

First, Cuervo-Cazurra (2006) find that investors from countries with high levels of corruption are undeterred by foreign corruption, and may even preferentially locate their activities in countries where corruption is widespread. While these results are promising, the hypothesised non-linearity is modeled in a very rigid way, while other dimensions of governance have been neglected. Concerns may also be raised about both the quality and representative nature of financial FDI flows reported by UNCTAD and about assuming that tax havens are the 'true' source countries. In addition, some key host countries are missing, e.g. India or China, and the industrial composition of FDI is not controlled for. Finally, the estimators of the parameters and the standard errors are likely to be biased as a Tobit estimator has been applied and the standard errors are not robust to both arbitrary heteroskedasticity and arbitrary autocorrelation.

In a second and related study, Cuervo-Cazurra and Genc (2008) investigate the determinants of the prevalence of S-MNEs among the largest foreign firms in the least developed countries, based on the hypothesis that S-MNEs, having acquired the ability to operate in poor institutional environments at home, have a competitive edge over their North counterparts in risky developing countries. As governance variables, they use the World Bank indicators (Kaufmann, Kraay, and Mastruzzi, 2004), and they obtain mixed results. While they find that the share of S-MNEs among the largest foreign firms in the least developed countries increases with poorer Regulatory Quality and lower Control of Corruption, it unexpectedly decreases with the strength of the Rule of Law, and is not affected by Voice and Accountability, Political Stability or Government Effectiveness. These results paint an ambiguous picture about the sensitivity of S-MNEs to poor governance. The methodological validity of this study is also unclear. The data come from UNCTAD reports which seem to identify an arbitrary number of ill-defined 'large' foreign affiliates for each country, casting doubts about the pertinence of the dependent variable. In addition, the sample is extremely small and the highly correlated governance indicators are all included together. This is likely to generate high multicollinearity and it could be responsible for some of the surprising 'wrong' signs found in the study. The methodology also greatly reduces their ability to control for other (bilateral) variables. Furthermore, the classification of countries into developed and developing can be questioned, e.g. Singapore as a South country, and there is an implicit assumption that the governance of source countries is broadly similar within each income group. Finally a Tobit model may not be appropriate to model proportions.

An implicit corollary of S-MNEs' resilience advantage hypothesis is that, despite their supposedly greater internationalisation, N-MNEs have not been able to acquire similar resilience through their own expansion in risky countries. 
This suggests that they have accumulated limited exposure to bad governance, potentially because their FSAs, initially acquired in their home country, tend not to be compatible with an underdeveloped institutional environment. From this perspective, we would expect that the quality of the source country's governance has less influence on the number of S-MNEs than on the number of N-MNEs. A large share of the S-MNEs are likely to have developed FSAs around filling institutional voids. This would both explain their success in difficult business environments at home and abroad and at the same time weaken the link between better governance and outward FDI. We are not aware of any paper addressing this specific source country-side issue from this perspective.

While the literature on the effects of better governance on outward FDI is limited, relative to that focused on inward FDI, Globerman and Shapiro (2002) find that improvements in 'governance infrastructure' increases both inflows and outflows of FDI. They argue that better governance tends to create the conditions for the successful foreign expansion of domestic firms. However, this effect is only statistically significant for developed countries, a finding that we interpret as supporting our hypothesis on the weaker link between governance and outward FDI in South countries.

\section{The mitigating role of bilateral ties hypothesis}

N-MNEs may not have the resilience advantage that S-MNEs have successfully developed in their home countries, but it is possible that both groups of MNEs benefit from the reduction in information and transaction costs that bilateral ties provide via their interaction with the destination country's governance conditions. For example, lower physical distance can increase knowledge of the institutions of a destination country via an increase in the propensity to travel there; a common language is likely to be particularly useful in dealing with bureaucrats and understanding regulations; migrant networks can not only increase the availability of information about the destination country in the source country, but can also act as informal contract enforcement institutions; a common religion, by fostering trust, may also act as an informal institution substituting to an absence of rule of law (Rauch, 2001; Goldberg, Heinkel, and Levi, 2005; Guiso, Sapienza, and Zingales, 2009). Hence, the sensitivity of N-MNEs to governance abroad may be source-country specific, albeit in much narrower bilateral way than the 'multilateral' resilience advantage held by S-MNEs. There is little existing evidence on the interaction between bilateral ties and investment response to governance conditions, and results by Tong (2005) are not encouraging. She finds, by splitting the destination countries in her sample between low and high bureaucracy-quality countries, that bilateral ties matter more in the latter group of countries.

As is clear from this succinct literature review, much remains to be uncovered or confirmed regarding the determinants of SS-FDI and how much they differ from those of NS-FDI. In this paper, we systematically investigate these three research 
questions: (i) the evolution stage hypothesis; (ii) the resilience advantage hypothesis; the mitigating role of bilateral ties hypothesis, exploiting a large bilateral FDI database.

\section{Econometric model and hypotheses}

Our empirical investigation will proceed in three stages.

\subsection{Commonalities and differences in NS-FDI and SS-FDI}

In a first stage, we wish to investigate whether SS-FDI and NS-FDI are equally sensitive to source-specific, destinationspecific and dyad-specific potential FDI determinants, that we have grouped in four categories. We summarise these variables and their expected impacts on NS-FDI and SS-FDI in Table 1. In agreement with the three theories that we have previously discussed, some FDI determinants are expected to have a different impact on SS-FDI and NS-FDI.

For our baseline empirical model, we adopt the following log-linear model:

$$
\begin{aligned}
\ln \left(E\left(F D I_{i j s} \mid x_{i j}, \alpha_{s}\right)\right) & =\alpha_{s} \\
& +\sum_{i=1}^{8} \beta_{i g} \text { Macroeconomic conditions } \\
& +\sum_{i=1}^{9} \gamma_{i g} \text { Geography and International agreements } \\
& +\sum_{i=1}^{6} \delta_{i g} \text { Bilateral ties } \\
& +\theta_{1 g} \text { Source governance }+\theta_{2 g} \text { Destination governance }
\end{aligned}
$$

where $F D I_{i j s}$ is our measure of bilateral FDI between source country $i$ and destination country $j$ in sector $s, x_{i j}$ is a vector of regressors, $\alpha$ s are sector-specific fixed effects. To test our predictions, we first estimate a fully unconstrained model, in the sense that the entire set of parameters is allowed to differ between the NS-FDI group and the SS-FDI group; subscript $g$ denotes that the estimated parameters are not constrained to be the same for the SS- and NS- FDI groups. Structural stability of the parameters across groups will be investigated through seemingly unrelated estimation, with a variance-covariance matrix adjusted for clustering at the country-pair level. Subsequently, in order to gain a better statistical insight in whether some parameters on key determinants truly differ across groups, we will obtain more precise 


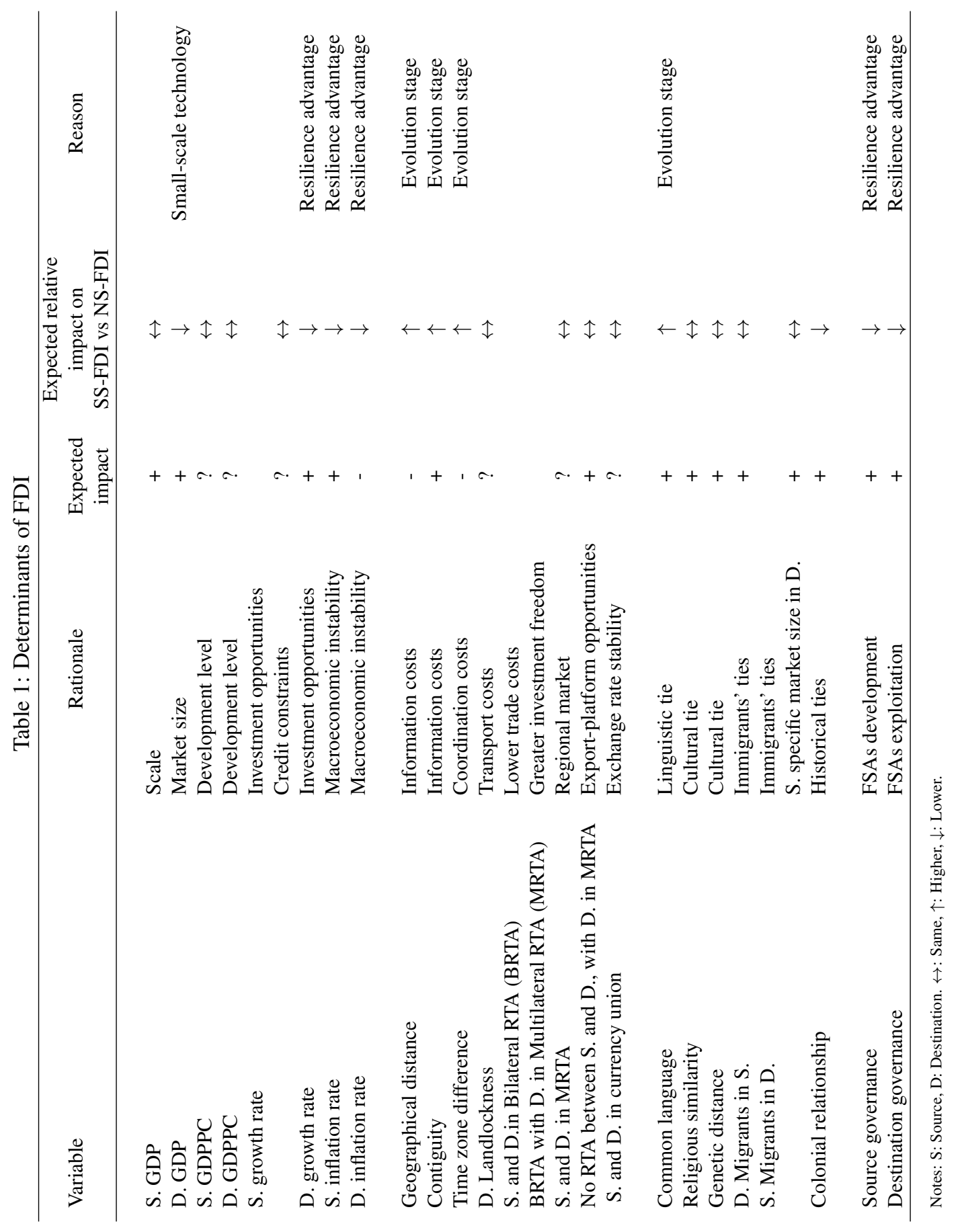


estimates by estimating a semi-constrained model in which we constrain some coefficients to be the same. ${ }^{6}$ We provide more details on the semi-constrained econometric model that we estimate in section 5.1.2.

We describe the four categories of FDI determinants in turn, and discuss whether we expect them to influence the location decisions S-MNEs and N-MNEs in a similar fashion.

\section{Macroeconomic conditions}

Source and destination GDP proxy for the scale and market size of the partner economies. We expect both variables to have a positive impact on NS-FDI and SS-FDI, even though the latter may be less sensitive to destination GDP, following the argument that S-MNEs' technology is better suited to small-scale markets than the allegedly large-scale technology of N-MNEs (Wells, 1983). Source and destination GDP per capita are included as indicators of the level of development of an economy. The expected impact of these variables is ambiguous, given that greater economic development is associated with a range of factors which may enhance or deter outward and inward FDI, such as financial development and liberalisation, physical infrastructure, larger consumer market or higher labour costs. Source and destination average growth rates are indicators of economic performance and investment prospects. The impact of this variable is also not clear-cut. On the source side, its overall effect on FDI depends on whether the substitution effect or the income effect dominates (Levy-Yeyati, Panizza, and Stein, 2007). On the one hand, faced with strong investment prospects at home, investors may substitute domestic investment to foreign investment, leading to lower outward FDI. On the other hand, the increase in cash flows achieved in economic expansions may relax any credit constraints that domestic firms face, allowing them to invest more abroad. From the destination perspective, we can expect that a sustained growth rate will attract FDI by signaling a growing number of investment opportunities. However, if some of the FSAs of S-MNEs truly relate to their ability to operate in business environments that have poor support for productive activities, the positive effect of growth of income per capita on inward FDI ought to be smaller for S-MNEs than for N-MNEs.

Source and destination inflation rate are common indicators of macroeconomic instability (Fischer, 1993). A desire to hedge against domestic macroeconomic risk should lead to more outward FDI, while the additional costs and uncertainty

\footnotetext{
${ }^{6}$ Our econometric approach can be interpreted as follows. In a first stage, we estimate separate regressions for the NS- and SS- FDI samples. In terms of the estimated coefficients, this is equivalent to estimating an empirical model using the full sample (SS- FDI and NS- FDI observations) but allowing each explanatory variable to have a distinct impact on SS-FDI and on NS-FDI, through their interaction with a South source country dummy. We call this model our fully unconstrained model. If our model is over-specified, in the sense that SS-FDI and on NS-FDI may be equally sensitive to certain determinants, the price to pay for avoiding any slope heterogeneity bias is less precise estimators. Hence, in a second stage, we strike a balance between bias and efficiency (a bias/variance trade-off) by statistically identifying those variables for which their effects are likely to be the same across investors and imposing this restriction on the equality of coefficients; interaction terms with the South dummy for these variables are dropped. Other variables are still allowed to have a different effect on each group of foreign investor, in what we refer to as our semi-constrained model, by keeping in our econometric model their interaction with the South (source country) dummy.
} 
generated by inflation should decrease inward FDI. Once again, we might expect a lower impact on outward and inward SS-FDI than on NS-FDI.

Geography and international institutions

Geographical distance is usually seen as a proxy for transport costs. Given that the bulk of FDI in South countries appears to be market-seeking, as suggested by the large impact of GDP on FDI found in many papers focusing on FDI in developing countries (Azémar and Desbordes, 2009), the proximity-concentration trade-off would imply that higher geographical distance increases aggregate FDI. However, empirical research has consistently found that physical distance decreases aggregate FDI, suggesting that it is a proxy for other costs which hinder FDI, such as transaction and information costs (Portes and Rey, 2005; Egger, 2008). Hence, we expect the coefficient on this variable to be negative. We also expect this effect to be larger (in absolute terms) for SS-FDI, as most S-MNEs are likely to be at the beginning of their internationalisation process and therefore still developing the resources and knowledge required to invest in unfamiliar and often physically distant countries (Johanson and Wiedersheim-Paul, 1975; Johanson and Vahlne, 1977). Conversely, N-MNEs are probably better positioned than S-MNEs to surmount the challenges of operating in a foreign market, thanks to greater international experience (Eriksson, Johanson, Majkgard, and Sharma, 1997). The inclusion of a contiguity dummy allows for a non-linear effect of physical distance. Following Stein and Daude (2007), time zone differences can be seen as an indicator of the coordination and management costs incurred by MNEs. We expect this variable to have a negative impact on both SS-FDI and NS-FDI, with a larger impact on the former, due to the relative international inexperience of S-MNEs. Destination landlockness is a proxy for transport costs. In line with our previous discussion on the overall nature of FDI, its impact on both SS-FDI and NS-FDI may be positive, even though higher transport costs greatly increase the cost of imported inputs (investment and intermediate goods) and the price of exported goods, which decrease the profitability of both export-oriented FDI and import-intensive horizontal FDI (UNCTAD, 2003).

A Regional Trade Agreement (RTA) usually leads to a reduction in regional trade barriers and investment restrictions. ${ }^{7}$ The RTA effects on intra-regional FDI are ambiguous. Lower tariffs can lead to a substitution of trade for horizontal FDI, but greater investment freedom and lower transaction costs may boost FDI, especially vertical FDI that exploits costreducing regional production networks to achieve greater efficiency. A bilateral RTA may also encourage horizontal FDI if it is signed with a partner country involved into a multilateral RTA; in addition to any favourable investment provisions, MNEs gain access to a larger market. Overall, a multilateral RTA is likely to have the greatest positive (least negative)

\footnotetext{
${ }^{7}$ Investment rules aimed at ensuring the fair treatment and protection of FDI are present in a number of RTAs. See (Velde te and Bezeme, 2006).
} 
impact on total FDI, followed by a bilateral RTA with a partner country involved in a multilateral RTA, and finally by a pure bilateral RTA. The effects of a destination country involved in a multilateral RTA on extra-regional FDI are likely to be positive as formation of the RTA should induce more export-platform FDI, motivated by a larger market which can be served through intra-regional trade taxed at a lower rate than the common external tariff (Blomstrom and Kokko, 1997; Neary, 2009). A currency union is a group of countries that share a single money. As any international institutional arrangement which reduces international trade costs, the impact of a currency union on FDI is ambiguous, depending on the type of FDI observed. Furthermore, exchange rate stability could encourage overall FDI, for instance by reducing uncertainty about the domestic value of repatriated foreign profits or simplifying costs and pricing decisions (Petroulas, 2007).

\section{Bilateral ties}

A common language should reduce information, communication and monitoring costs (Goldberg, Heinkel, and Levi, 2005). A linguistic tie should have a positive impact on FDI, with a larger effect on SS-FDI given that S-MNEs may have less resources and experience to cope with the higher costs and operating difficulties related to a foreign language. Data come from Head, Mayer, and Ries (2010). Religious similarity may foster trust, which can act as an informal contractenforcement institution (Guiso, Sapienza, and Zingales, 2009). Hence, cultural ties should have a positive impact on FDI. Genetic distance is believed to be a good proxy for cultural, and potentially physical, differences (Guiso, Sapienza, and Zingales, 2009). Higher cultural distance should decrease trust and therefore we expect this other proxy for cultural ties to have a negative impact on FDI.

The stock of migrants from destination country $j$ in source country $i$ should help to both identify investment opportunities and reduce informational and transaction costs in the destination country $j$ for investors form source country $i$ (Rauch, 2001; Javorcik, Özden, Spatareanu, and Neagu, 2011). The stock of migrants from source country $i$ in destination country $j$ may have the same positive attributes, but, in addition, it may also indicate the size of the destination country's market for the goods of the source country, i.e. a 'taste similarity' effect. Hence, we expect both measures of immigrants' ties to have a positive effect on FDI but, with a larger impact when the effects of the stock of migrants in the destination country are observed. We do not necessarily expect SS-FDI and NS-FDI to demonstrate diverging sensitivities to cultural similarity or migrant networks, given that some of the benefits that these bilateral ties provide are unlikely to be attainable through experience derived from greater internationalisation. A past colonial relationship is likely to increase foreign investors' business and institutional knowledge of the destination country via common history, the existence of 
long-established business networks and a bilateral emphasis on diplomatic, economic and cultural exchanges (Makino and Tsang, 2011). Historical ties should foster FDI, but with a greater impact on NS-FDI as South-South colonial links are much more ancient.

\section{Governance}

Better source governance should help domestic firms develop the FSAs necessary to expand abroad. However, this positive link between good governance and outward FDI will be weaker if part of the FSAs of some MNEs has in fact emerged from the need to circumvent or fill the institutional voids they faced in their source country. The mix between firms exploiting bad governance conditions and firms hindered by institutional development changes as governance improves. These resilience skills are more difficult to acquire or retain, and they lose value (at least at home), leading to a shift towards MNEs which benefit from better governance conditions. Hence, better source governance should have a positive impact on both NS-FDI and SS-FDI, but with a lower impact on the latter, given the role that a resilience advantage is likely to play when operating in South countries.

In the same fashion, better destination governance should allow MNEs to fully exploit their FSAs. However, if SMNEs truly possess a resilience advantage which complements their other FSAs, ${ }^{8}$ good governance conditions ought to matter less for them than for their Northern counterparts, and may even lead them to invest in relatively risky countries if the expected returns to investment, discounted for risk, are sufficiently high. For these reasons, the impact of destination governance on FDI should be positive and larger for N-MNEs.

\subsection{A direct test of the resilience advantage hypothesis}

In a second stage, we can investigate more directly the hypothesis that S-MNEs are better able to deal with poor governance abroad thanks to their experience of similar conditions at home, by interacting Source (S.) governance with Destination (D.) governance (gov.) in our semi-constrained model:

$$
\begin{aligned}
& \ln \left(E\left(F D I_{i j s} \mid x_{i j}, \alpha_{s}\right)\right)=\ldots \\
&+\theta_{1} \text { S. } \text { governance }_{i}+\theta_{2} \text { D. governance } \\
& j
\end{aligned}
$$

\footnotetext{
${ }^{8}$ The resilience advantage cannot be the sole FSA of S-MNEs given that domestic firms in the foreign country will also possess the knowledge of how to deal with poor governance.
} 
If the resilience advantage exists, we expect $\theta_{3}$ to be statistically significant and positive, as better public governance in a source country implies less experience of poor institutional quality. These results will be followed by a series of robustness checks.

\subsection{A direct test of the mitigating role of bilateral ties}

In a third and final stage, we examine whether bilateral ties can influence the sensitivity of NS-FDI and SS-FDI to destination governance, by interacting Destination governance with each bilateral tie in our semi-constrained model:

$$
\begin{aligned}
& E\left(F D I_{i j s} \mid x_{i j}, \alpha_{s}\right)=\ldots
\end{aligned}
$$

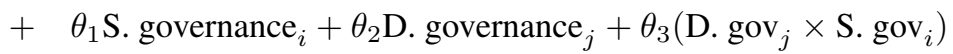

$$
\begin{aligned}
& +\phi_{1}\left(\text { D. } \operatorname{gov}_{j} \times 1 /(\ln (\text { Geographic distance }))_{i j}\right) \\
& +\phi_{2}\left(\text { D. } \operatorname{gov}_{j} \times \text { Common language }_{i j}\right)+\phi_{3}\left(\text { D. } \text { gov }_{j} \times \text { Religious similarity }_{i j}\right) \\
& +\phi_{4}\left(\text { D. } \operatorname{gov}_{j} \times \text { D. Migrants in S. } \cdot{ }_{j i}\right)+\phi_{5}\left(\text { D. } \operatorname{gov}_{j} \times \text { S. Migrants in D } \cdot_{i j}\right)
\end{aligned}
$$

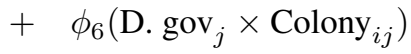

We expect the $\phi$ s to be negative. That would mean that a bilateral tie mitigates the impact of destination governance, rendering the latter source-specific, including for N-MNEs.

\section{Data and estimation method}

\subsection{Dependent variable}

Our dependent variable corresponds to the number of distinct MNEs, headquartered in source country $i$, owning majorityowned foreign affiliates in sector $s$ of destination developing country $j$, as reported by the UNCTAD on the Investment Map website in November 2007. ${ }^{9}$ There are 144 source countries (developed and developing), 104 destination countries (only developing countries, excluding economies in transition that belong to the European Union) and three broad sectors (primary, secondary, tertiary). Given that we are interested in investigating how the sensitivity of MNEs to destination

\footnotetext{
${ }^{9}$ http://www.investmentmap.org/invmap/index.aspx?prg=1. The original source of the data is The Global Reference Solution, from Dun \& Bradstreet. Information is only provided on foreign affiliates located in developing countries and economies in transition that do not belong to the European Union. Hence, determinants of North-North and South-North FDI could not be investigated. In addition, while it would have been interesting to investigate the determinants of N-S FDI and SS-FDI at the extensive (number of parent companies) and intensive (volume of investment) margins, data limitations prevent us from doing so. The only information that is systematically available on the Investment Map is that on the number of foreign affiliates and the number of distinct parent companies.
} 
governance is shaped by governance conditions at home, we omit from the final sample all tax haven countries, ${ }^{10}$ as they are likely to be the source and destination of a large volume of "roundtripping" and "trans-shipping" FDI flows for which their firms are not responsible or which does not remain in the country. ${ }^{11}$ The database maintained by Dun \& Bradstreet records the ownership information of firms, such as whether they are majority-owned by a foreign investor from a given source country. Hence, the UNCTAD Investment Map database on foreign affiliates only includes positive counts of distinct MNEs and of foreign affiliates by design. As a result, the absence of positive values does not mean that the information is missing but indicates that Dun \& Bradstreet has no record of a firm majority-owned by a foreign investor from a given source country in one of the broadly defined sectors. Given that we are not restricted by a lack of information on explanatory variables when the count is reported to be equal to zero, we can additionally populate our dataset with zero values, which thus correspond to industry-country-pairs for which no FDI has been observed. In that way, our estimators are not affected by a left-truncation at zero bias, and, relative to a zero-truncated regression model, we gain in efficiency as we are able to exploit the information provided by the zero values (Wooldridge, 2002 ). ${ }^{12}$

Figure 1 show the main sources and recipients of South FDI, as measured by the number of distinct foreign parent companies in a given source or destination country. Unsurprisingly the main sources and recipients of FDI tend to be the G8 countries and the regional economic powers, such as Brazil, South Africa, Russia, India or China. In the Appendix, Table 15 provides the full list of source and destination countries. For comparison, figure 2 shows the main sources and recipients of South 'financial' FDI, as identified by the financial FDI stocks in 2007 reported by UNCTAD in a given source or destination country. ${ }^{13}$ It can be seen that the two FDI proxies paint broadly the same picture, suggesting that the intensive and extensive margins of FDI tend to largely overlap each other; the coefficient of correlation for inward FDI is 0.71 while the coefficient of correlation for outward FDI is 0.88 .

There are multiple advantages to using this database. First, it is likely to generate a more accurate picture of FDI patterns than FDI data retrieved from balance of payments data, since the latter are increasingly seen as a poor proxy of multinational activities (Lipsey, 2007). Second, it is unique in providing bilateral data on FDI, with a wide coverage of countries and sectors. While other bilateral FDI databases exist, they are not suitable for the analysis of S-S FDI which is the main focus of this paper. For instance, the OECD International Direct Investment Statistics only report bilateral FDI

\footnotetext{
${ }^{10}$ Based on Hines and Rice (1994), we omit from the final sample Antigua and Barbuda, Bahamas, Bahrain, Barbados, Belize, Cyprus, Dominica, Grenada, Ireland, Jordan, Lebanon, Liberia, Luxembourg, Maldives, Malta, Panama, Saint Kitts and Nevis, Saint Lucia, Saint Vincent and the Grenadines, Singapore, Switzerland, Vanuatu.

${ }^{11}$ Roundtripping refers to the situation where different treatments of foreign and domestic investors encourage the latter to channel their funds into special purpose entities (SPEs) abroad in order to subsequently repatriate them in the form of incentive-eligible FDI. With trans-shipping, funds channeled into SPEs in offshore financial centres are redirected to other countries, leading to strong divergences between the source country of the FDI and the ultimate beneficiary owner.

${ }^{12} \mathrm{An}$ additional benefit of using the NBRM over a zero-truncated NBRM is that convergence is much more easily achieved with the former.

${ }^{13}$ Data are available at http: / / www. unctad. org/Templates/Page. asp? int ItemID=5823\&lang=1
} 
Figure 1: Source and destination countries of real FDI stocks

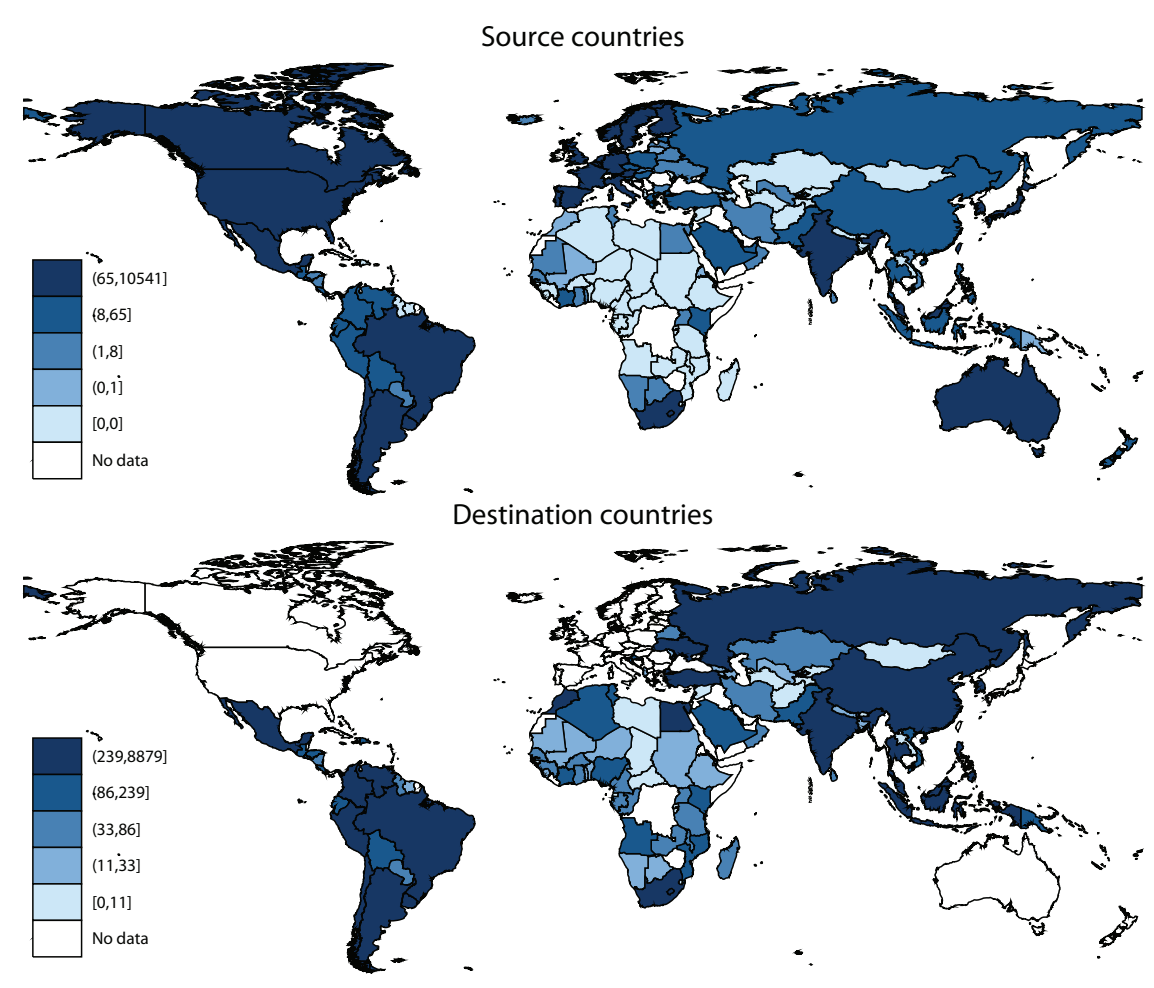

Note: Class breaks correspond to quantiles of number of distinct foreign parent companies owning majority-owned foreign affiliates.

between OECD countries and a partner country. As a result, use of the OECD FDI database would prevent us to analyse the determinants of South-South FDI, which are the main focus of this paper. ${ }^{14}$ Third, it not only gives the number of foreign affiliates but also the number of distinct parent companies. We employ the number of distinct MNEs as our dependent variable as this variable is likely to offer a better guarantee that the FDI responses we estimate reflect a typical behavioral pattern and are not dominated by the behaviour of a few large MNEs.

However, the use of count data on distinct parent companies in a cross-sectional setting also has limitations. It is easy to imagine a cross-sectional situation in which the number of bilateral projects is the same in two different countrypairs, but where the total volume of investment is nevertheless higher in the second pair as a result of lower political risk in the destination country. South and N-MNEs may differ in their mode of (minority-owned vs. majority-owned), and desire to, entry due to technological differences. In that context, our count data may generate a confusing picture of FDI determinants. Our results could also be influenced excessively by the behaviour of small, and plausibly more numerous, foreign firms. Finally, we cannot control for country-pair specific effects, which would pick up any unobserved time-

\footnotetext{
${ }^{14}$ There are two other issues with this database. First, some bilateral data are not reported for confidentiality reasons, e.g. outward position of Australia in India or China in 2006. Second, as previously argued, financial FDI stocks may be a poor proxy of the activities of MNEs. These financial stocks only correspond to one of the channels used by MNEs to finance their foreign activities, they are evaluated at historical costs and each country does not necessarily have the same reporting criteria.
} 
Figure 2: Source and destination countries of financial FDI stcoks

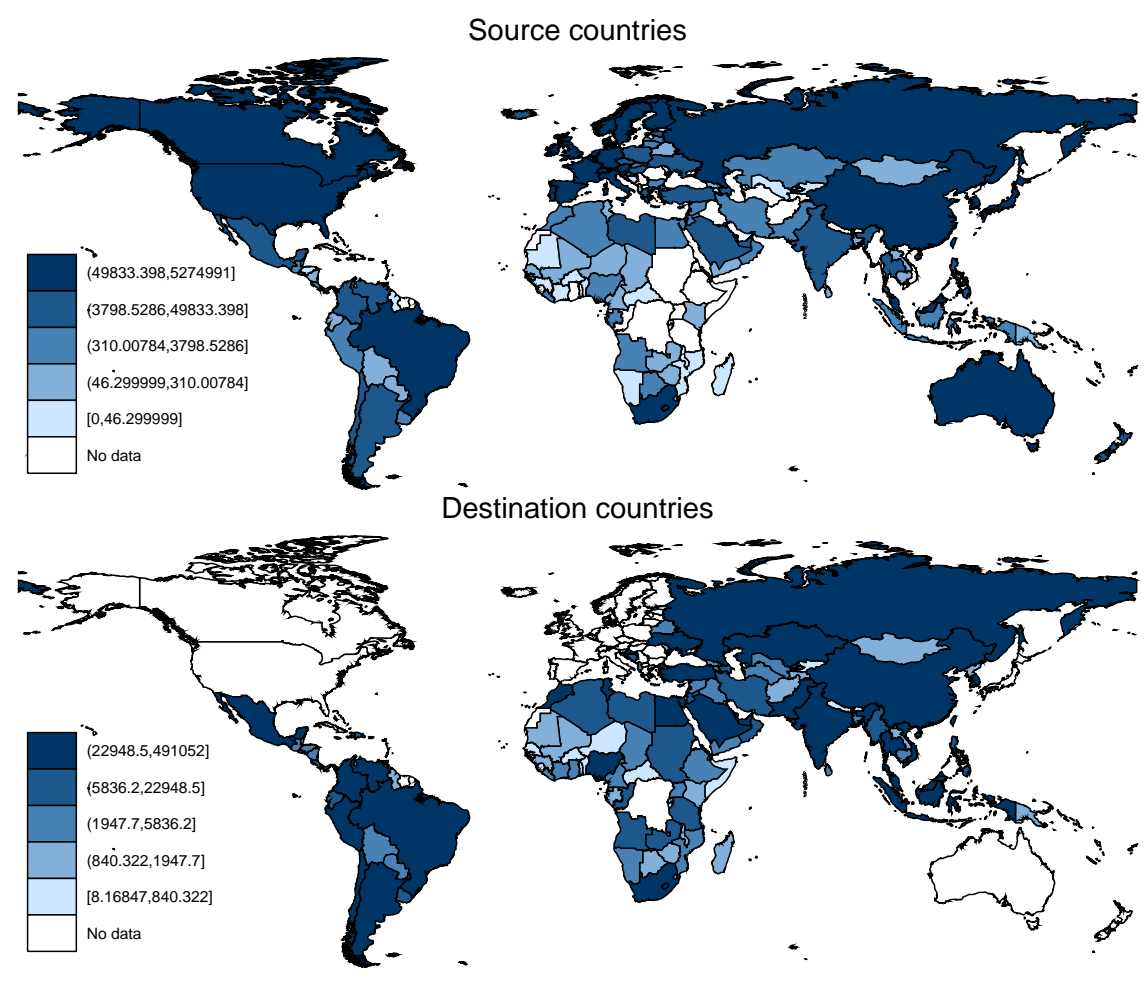

Note: Class breaks correspond to quantiles of financial FDI stocks, as reported by UNCTAD

invariant factor affecting bilateral FDI. These worries are to a certain extent valid. The fact that we do not observe the volume of investment may obscure the sensitivity of FDI to some determinants, but we believe it is very unlikely that this factor would play a role in the observation of potential behavourial differences between S-MNEs and N-MNEs. We will show in our robustness checks how we can test for the technological intensity of the FSAs of N-MNEs and S-MNEs. The criticism that the estimates may fail to capture the 'typical' behaviour of MNEs can also be directed at investment data, which may give too much weight to very large and outlying firms. Finally, we have tried to reduce any omitted variable bias by including a large list of regressors.

\subsection{Explanatory variables}

We next present the sources of our explanatory variables in turn and explain why all our variables have been averaged over the 1996-2004 period.

Macroeconomic conditions

Source and destination GDP (in 2005 PPP \$US) and Source and destination average growth rate come from 
Heston, Summers, and Aten (2009). Source and destination inflation rate come from the IMF WEO online database. ${ }^{15}$

Geography and international institutions

Geographical distance (population-weighted ${ }^{16}$ ), the contiguity dummy, time zone differences, the destination landlockness dummy come from Mayer and Zignago (2006) and Head, Mayer, and Ries (2010). The dummies for a pure bilateral RTA, a bilateral RTA with a partner country involved in a multilateral RTA, a multilateral RTA,a destination country involved in a multilateral RTA and a currency union are based on the international agreements coded by José de Sousa. ${ }^{17}$.

\section{Bilateral ties}

The common language dummy, which indicates a language spoken by at least $9 \%$ of the population in both countries, come from Head, Mayer, and Ries (2010). Religious similarity is the sum of the products of the fraction of individuals in the source and destination countries who share the same religion $r$. Initial data come from McCleary and Barro (2006), are for the year 2000, and there are seven different religions $r$ (Catholic, Protestant, Orthodox, Jewish, Muslim, Hindus, Buddhist). The genetic distance corresponds to genetic differences between the populations of the partner countries, and has been created by Spolaore and Wacziarg (2009). The stock of migrants from destination country $j$ in source country $i$ and the stock of migrants from source country $i$ in destination country $j$ are for the year 2000 and come from the World Bank online Global Bilateral Migration Database. ${ }^{18}$ The past colonial relationship dummy come from Mayer and Zignago (2006).

\section{Governance}

Data on the quality of countries' public governance come from Kaufmann, Kraay, and Mastruzzi (2008). They evaluated six dimensions of public governance, on the basis of polls of experts or surveys of businessmen/citizens. The categories are (i) Voice and Accountability (VA), (ii) Political Stability (PS), (iii) Government Effectiveness (GE), (iv) Regulatory Quality (RQ), (v) Rule of Law (RL) and (vi) Control of Corruption (CC). VA and PS attempt to capture the process by which those in authority are selected and replaced, GE and RQ are related to the ability of the government to

\footnotetext{
${ }^{15}$ For a few countries, the inflation rate is negative. Given that we use the log of this variable, we used prior to its transformation its absolute value; like inflation, persistent deflation can clearly be seen as indicating macroeconomic instability.

${ }^{16} \mathrm{~A}$ population-weighted geographical distance is the distance between two countries based on bilateral distances between the biggest cities of those two countries, those inter-city distances being weighted by the share of the city in the overall country's population. See Mayer and Zignago (2006) for further details.

${ }^{17}$ http://jdesousa.univ.free.fr/data.htm

${ }^{18}$ http://data.worldbank.org/data-catalog/global-bilateral-migration-database
} 
formulate and implement sound policies, while RL and CC assess the respect of citizens and the state for the institutions which govern their interactions.

All variables have been averaged over the 1996-2004 period for two main reasons. First, averaging reduces the influence of short-run fluctuations. Second, these time-averaged data allow us to account, admittedly imperfectly, for the different investment and institutional paths of countries. More specifically, our dependent variable can be conceived the cumulative outcome of past investment decisions, shaped by the perceived values of the determinants at the times decisions were made. These values are likely to differ from their current values. For instance, even though institutional risk in the source country may currently be low, MNEs, and their managers, may have been exposed to higher levels of risk in the past, allowing them to gain practical knowledge on how to operate, today, in difficult business conditions. From the host country perspective, the current quality of a host country's public governance may not perfectly reflect past institutional quality. ${ }^{19}$ Assuming that a given host country only recently achieved good public governance, it is likely that it will not be host, ceteris paribus, to as many foreign affiliates as a country that developed good institutions a long time ago. Timeaveraged data allow us to accommodate partly these country-specific development paths. Summary statistics are provided in Tables 13 and 14 in the Appendix. ${ }^{20}$ Our distinction between North and South countries is based on the World Bank income classification circa $2000{ }^{21}$ North countries are high-income countries, while South countries correspond to the other countries.

\subsection{Estimation method}

Our dependent variable is the number of distinct MNEs, headquartered in source country $i$, owning majority-owned foreign affiliates in sector $s$ of destination developing country $j$. Given that this is a count variable, which can only take nonnegative integer values, we adopt a count data model. ${ }^{22}$ We deal with overdispersion (conditional variance greater than conditional mean) by employing a negative binominal regression model (NBRM) with standard errors clustered at the country-pair level. Despite the large presence of zeros in our sample (about $95 \%$ of the values), we do not resort to a multi-index model, such as a zero-inflated negative binomial model, as there is no a priori reason to believe that zero and non-zero values come from different data generating processes. For instance, we expect that it is highly unlikely that any FDI will occur between small and distant countries, a pattern that should be captured adequately by our regressors and

\footnotetext{
${ }^{19}$ Values of the correlation coefficients between the 1996 and 2004 values of the six public governance dimensions range between 0.70 (CC) and 0.88 (VA).

${ }^{20}$ As a direct consequence of this averaging, despite being initially dummies, our RTA variables lose their binary nature since some agreements have not been in force during the entire 1996-2004 period.

${ }^{21}$ http: / / go. worldbank . org/ZSQKYFU6J0

${ }^{22}$ For a comprehensive exposition of count data models, see Winkelmann (2008).
} 
the assumption of a negative binomial distribution, which increases the probability of a zero count relative to the Poisson distribution. This line of thinking is supported by the similarity of the observed probability for the absence of FDI with the average predicted probability from the NBRM in the entire sample (0.951 vs. 0.948), the North-South FDI sub-sample (0.805 vs. 0.794$)$ and the South-South sub-sample (0.985 vs. 0.984$)$. Furthermore, these close values suggest that it is reasonable to assume, as we have done, that non-reported bilateral FDI values are 'true' zero values, given that they are well explained by our econometric model.

Our data are cross-sectional. Hence, we cannot include country or country-pair effects to account for unobserved heterogeneity. However, it is important to note that using country-pair effects would change the interpretation of the estimates, since country-pairs in which there were never any projects would implicitly be dropped from the sample; intuitively, these groups could not contribute to the estimation of the parameters as their lack of intra-group variation provides no additional exploitable information. In this context, the fixed effects estimates would no longer reflect the impact of a given regressor on the probability of overcoming the country-pair specific hurdle to invest, in addition to its impact on the number of affiliates. ${ }^{23}$

Finally, in our regressions, we introduce each governance dimension one at a time given their high correlations. To do otherwise would generate very imprecise estimates.

\section{Empirical results}

\subsection{Determinants of NS-FDI and SS-FDI: how much do they differ?}

\subsubsection{Fully unconstrained model}

As previously outlined, we start our empirical investigation by estimating a fully unconstrained model, in which the impact of each FDI determinant is allowed to be different for NS-FDI and SS-FDI. While for each column the estimated coefficients belong to the same regression, we break down the presentation of our results in four tables, along the typology of FDI determinants adopted in section 3.1. Table 2 focuses on macroeconomic conditions and sectoral allocation, Table 3 deals with geography and international institutions, Table 4 concentrates on bilateral ties and Table 5 examines source and destination governance. In each table, the variable names shown in bold indicate that the difference in coefficients between the two groups has been found to be statistically significant at the 5\% level or less in at least five of the econometric models

\footnotetext{
${ }^{23}$ However, as noted in footnote 34 , for some regressions in which we focus on bilateral effects, we find that our results are robust to the joint inclusion of source and destination countries' dummies.
} 
estimated. However, we do not only restrict our attention to those variables alone as the estimated coefficients may diverge substantially enough across the regressions to warrant some discussion of the factors underlying these differences. Finally, as noted above, to avoid multicollinearity issues, we use the six governance variables one at a time.

\section{Macroeconomic conditions}

Table 2 shows that the scale of NS-FDI and SS-FDI is related to the size of the involved countries. The higher impact of a source country's market size on SS-FDI may reflect the fact that S-MNEs, which tend to be at an early phase of internationalisation, are more reliant on the advantages provided by a large home market, such as financial strength resulting from a large domestic consumer base, than N-MNEs, which are more likely to have geographically dispersed activities. On the other hand, the lower impact of the destination country's market size on SS-FDI fits well with Wells (1983)'s hypothesis that S-MNEs have a 'small-scale' technology advantage over N-MNEs.

Higher income per capita in a South source country tends to increase FDI whereas the opposite is true for a North source country. These drastic opposite effects suggest that the correlation between this variable and other unobserved attributes is discontinuous. Depending on the group observed, income per capita may proxy for a factor enabling or inhibiting FDI. For South countries, column (6) suggests that higher income per capita appear to mainly capture the positive effects on outward FDI of greater Government Effectiveness, while for North countries, higher income per capita may indicate more FDI-substitute domestic investment opportunities. ${ }^{24}$

For both groups, MNEs tend to invest less abroad when their home economies grow quickly. This countercyclical effect echoes the findings of Levy-Yeyati, Panizza, and Stein (2007) and appears to be more pronounced for NS-FDI. NS-FDI also seems to be much more responsive to good economic performance in a destination country than SS-FDI. Inflation has a negative effect on outward FDI but the coefficient is not robust to the introduction of different governance dimensions, suggesting that this effect is really a macroeconomic symptom of weak institutions (Acemoglu, Johnson, Robinson, and Thaicharoen, 2003). Two arguments can be put forward to explain why NS-FDI and SS-FDI tend to be located in countries with high inflation rates. For various reasons, those countries may have been considered attractive by foreign investors, whose capital inflows have led to macroeconomic overheating. Capital account liberalisation, which has been found to have a positive impact on FDI in developing countries (Noy and Vu, 2007), may have facilitated this process. Alternatively, North and S-MNEs may have decided to undertake FDI projects in crisis-affected countries in order

\footnotetext{
${ }^{24}$ These results could also simply reflect the poor outward FDI performance of oil-rich countries. However, for most regressions, the negative sign on the coefficient of North source income per capita remains when we omit those countries or include a source oil-exporting country dummy. Results are not reported but are available on request/
} 


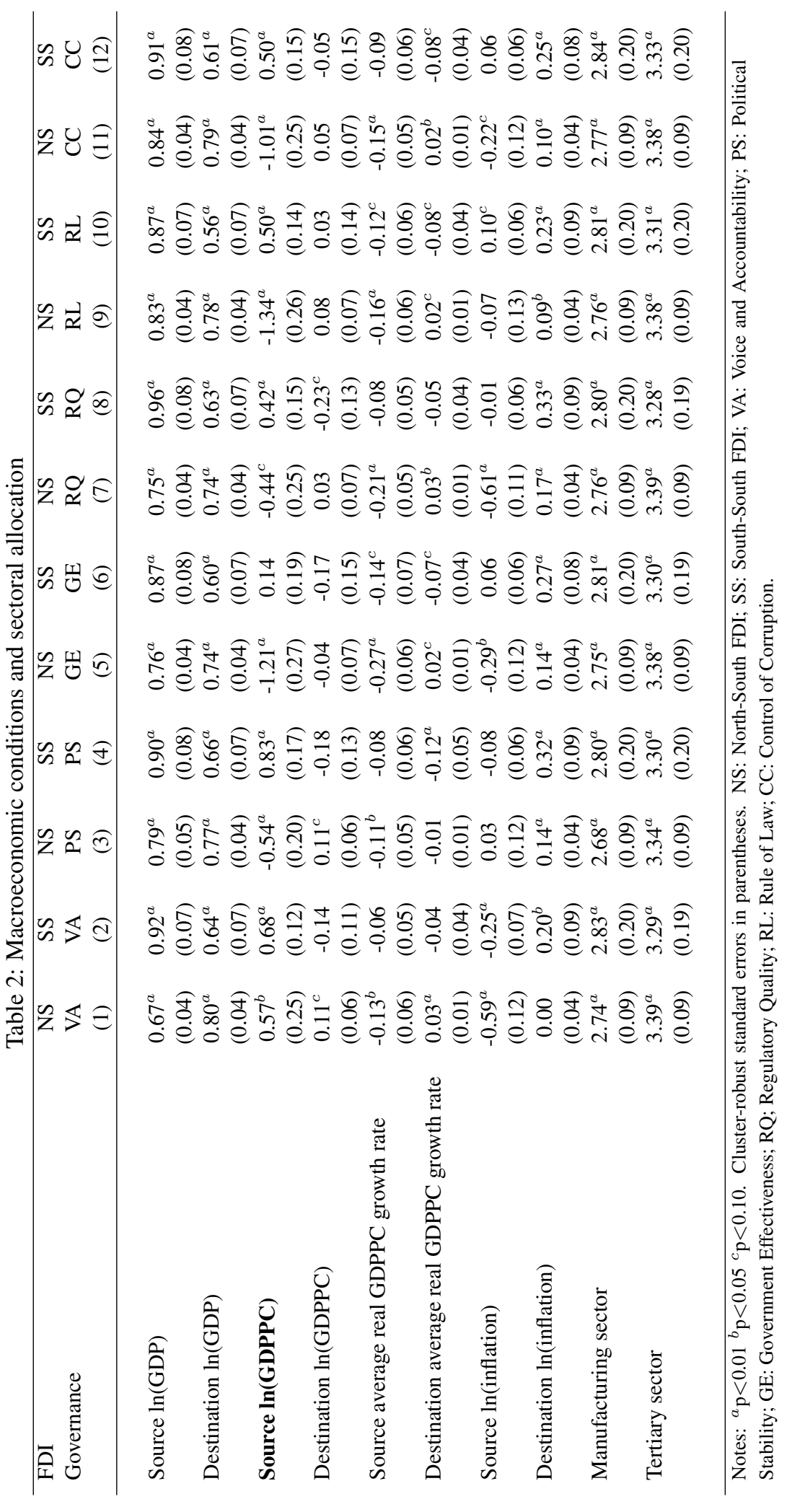


to take advantage of fire-sales of domestic assets or, alternatively, to profit from a crisis-induced temporary reduction in domestic competition to establish new ventures, with the aim of gaining additional market share or securing a first-mover advantage. $^{25}$ Overall, the fact that S-MNEs are much less sensitive to macroeconomic risk than N-MNEs in their source and destination countries is in line with what we expect if S-MNEs possess a resilience advantage.

Both NS-FDI and SS-FDI take place primarily in the tertiary sector. This is followed by the secondary sectors, and, far behind, by the primary sector. On average, there is about 30 times and 15 times more FDI in the tertiary and secondary sectors respectively, than in the primary sector. The sectoral composition of NS-FDI and SS-FDI does not substantially and statistically differ, and this finding alleviates any concerns of aggregation bias.

\section{Geography and international institutions}

Table 3 shows that geographical distance exerts a negative impact on FDI, with a larger (in absolute terms) impact of distance on SS-FDI. This result can be interpreted as evidence that the lack of international experience of S-MNEs, relative to N-MNEs, amplifies the transaction and information costs that are likely to be positively correlated with physical distance. The coefficient on contiguity is positive but never statistically significant, suggesting that that we have adequately controlled for FDI determinants related to close physical proximity. ${ }^{26}$ The impact of a time-zone difference is negative, as expected, but is rarely statistically significant. Both NS-FDI and SS-FDI tend to avoid landlocked countries, possibly because higher transport costs greatly increase both the cost of imported inputs (investment and intermediate goods) and the price of exported goods, which reduce the profitability of export-oriented FDI and import-intensive horizontal FDI (UNCTAD, 2003).

Bilateral RTAs appear to have little robust impact on FDI. On the other hand, the existence of a multilateral RTA (MRTA) increases intra-regional SS-FDI and extra-regional NS-FDI, implying that the benefits that a multilateral RTA may provide to a foreign investor outweigh any trade-for-FDI substitution effects. These results also confirm those of MacDermott (2007), who finds that NAFTA, the largest MRTA involving North and South countries, has increased extraregional FDI but not intra-regional FDI. Finally, a currency union does not seem to boost SS-FDI.

\footnotetext{
${ }^{25}$ High inflation rates may also proxy for some unobserved characteristics of Latin American and Caribbean (LAC) countries, notorious for their historical volatile macroeconomic conditions. However, in unreported regressions, inclusion of a regional LAC dummy does not substantially modify the results.

${ }^{26}$ In unreported regressions, we find that this result can be explained by the presence of migrant networks in our model. If we omit them from the model, the coefficient on contiguity gains size and statistical significance.
} 


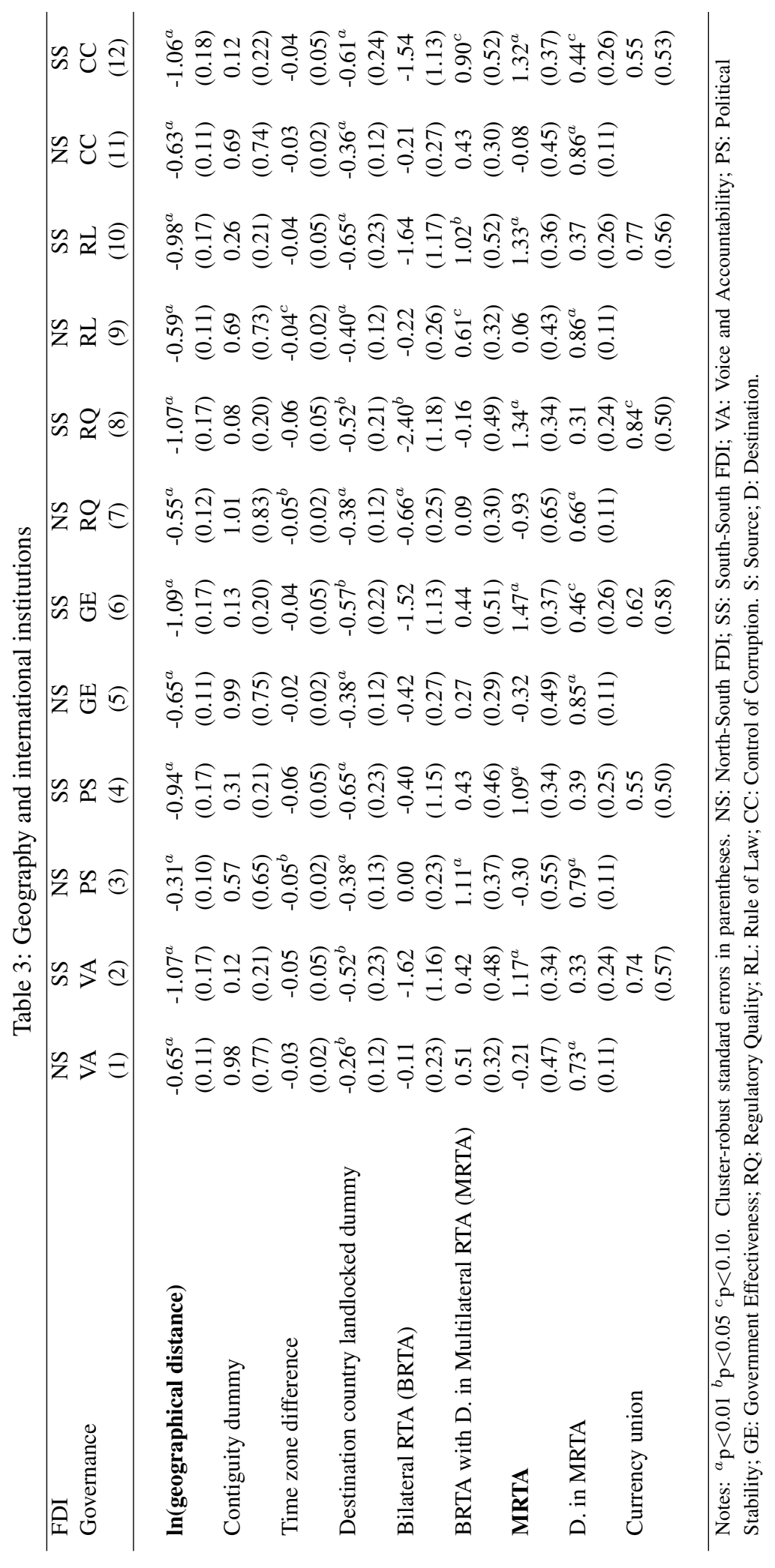




\section{Bilateral ties}

Table 4 indicates that linguistic similarity influences both NS-FDI and SS-FDI, even though it appears to be more important for the latter, presumably because S-MNEs, which are likely to be at an earlier internationalisation stage than N-MNEs, have less capacity to cope with the difficulties of operating in foreign-language environment. Religious similarity strongly influences NS-FDI but not SS-FDI. Migrant networks foster NS-FDI and SS-FDI FDI indistinctively. As expected, migrants in the destination country appear to play a (frequently statistically significant) larger role in facilitating bilateral FDI than migrants in the source country, thanks to their additional contribution to the creation of a market for the goods of the source country. The coefficient on the genetic distance variable tends to be statistically significant, but contrary to our expectations, is positive. It is possible, as argued by Giuliano, Spilimbergo, and Tonon (2006), that genetic distance is in fact a proxy for transport costs, which increase horizontal FDI. ${ }^{27}$

Finally, as commonly found in the literature, colonial history has a strong positive influence on NS-FDI. On the other hand, it has little impact on SS-FDI, presumably because the colonial link was dissolved long ago and/or because any effect is already being captured by geographical variables.

\section{Governance}

We look at the impact of governance in Table 5. Better governance in the source country tends to increase both NSFDI and SS-FDI but, in general, the former is much more responsive to an improvement of governance than the latter. In addition, they do not share the same sensitivity to improvements in a given governance dimension. For instance, North outward FDI is strongly influenced by Rule of Law whereas the most important dimension to foster South outward FDI is Government Efficiency. The same pattern can be observed when we investigate the impact of better governance in the destination country. While both NS-FDI and SS-FDI are similarly sensitive to a destination country's Regulatory Quality, a result which echoes the findings of Globerman and Shapiro (2002) and Daude and Stein (2007), SS-FDI appears to be little deterred by the absence of Rule of Law and Control of Corruption. Even though we cannot statistically reject the equality of coefficients in most instances, the systematic weaker economic impact of source and destination governance on S-S FDI relative to that on N-S FDI is supportive of the hypothesis that S-MNEs possess a resilience advantage. This suggests that S-MNEs are more likely to originate from, and invest in, countries characterised by institutional voids than their Northern counterparts.

\footnotetext{
${ }^{27}$ In a first stage, the authors show that geography (e.g. bilateral distance, the presence of major mountains chains, common seas) is not only a determinant of bilateral transport costs but can also help to explain genetic distance, presumably by having influenced migration patterns and genetic drift. This strong correlation between transport costs and genetic distance leads the authors to suspect that the impact of genetic distance on trade mostly reflects an omitted variable bias, in the context of econometric models imperfectly controlling for transport costs. Indeed, in a second stage, they find that genetic distance exerts no independent impact on bilateral trade once transport costs are properly accounted for.
} 


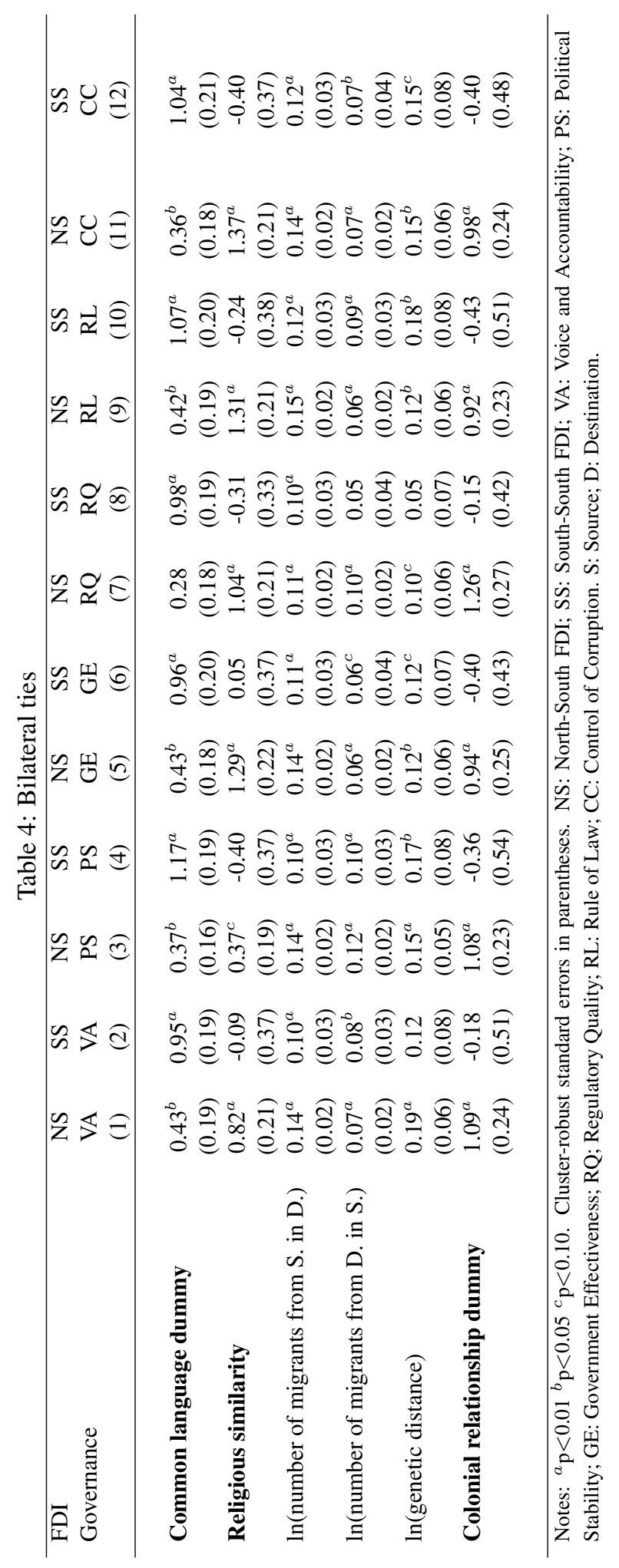




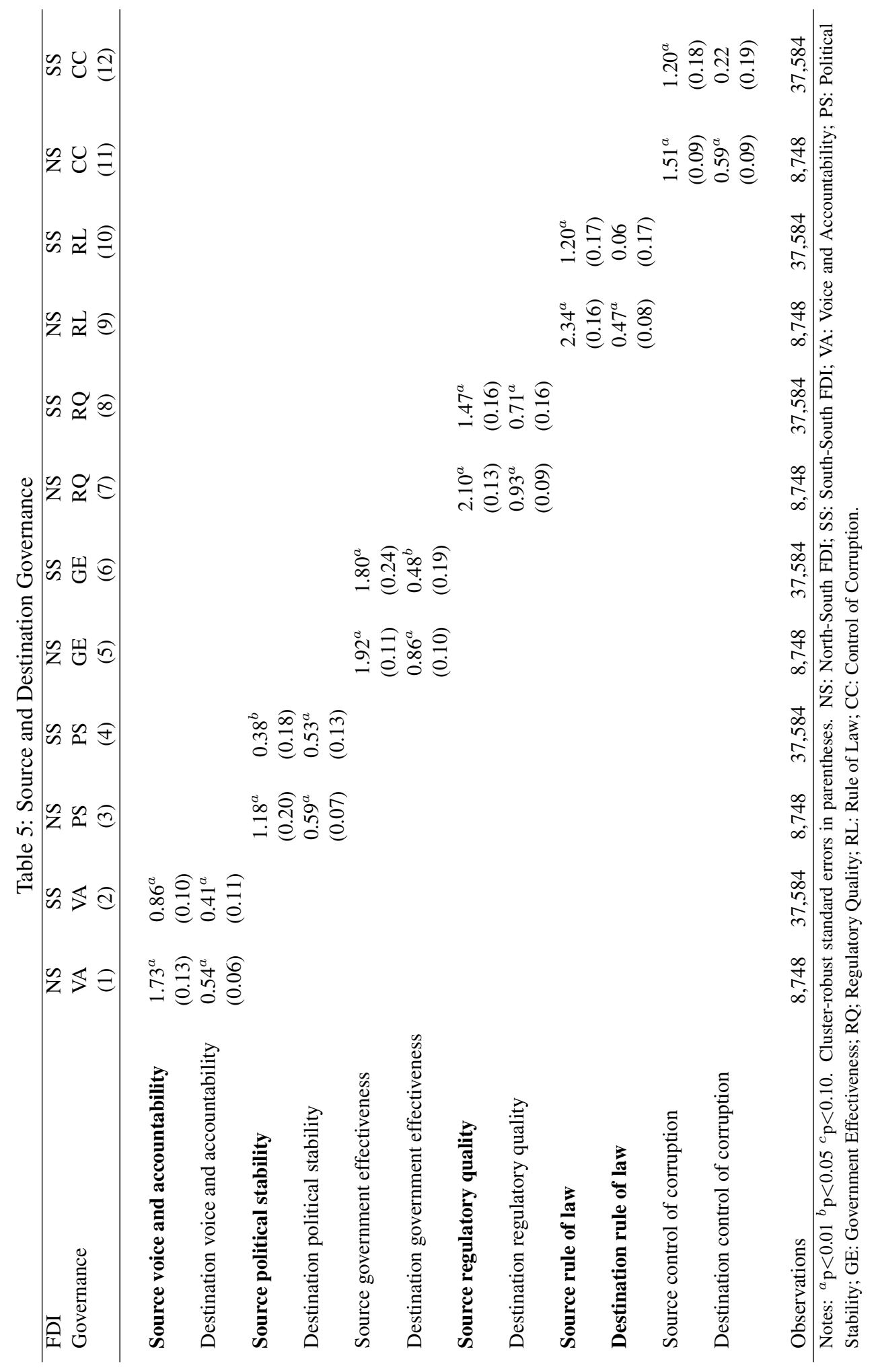




\subsubsection{More efficient estimates of NS-FDI and SS-FDI responses to governance}

A better statistical insight on whether South and N-MNEs respond differently to governance may be gained by estimating a model in which we do not allow all coefficients to differ across groups. More specifically, we estimate a semi-constrained model in which we include interaction terms with a South source country dummy only for those variables, besides the governance variables, that have been found to have a systematically statistical different impact across groups (the variables shown in bold in previous tables). ${ }^{28}$ Other variables are assumed to have the same impact on both groups of investors. This approach, in which we impose a set of restrictions, is equivalent to deleting the irrelevant variables from an overspecified model -in our case a fully-interacted model, in order to obtain more efficient estimates of all remaining parameters. ${ }^{29}$ We estimate therefore the following econometric model:

$$
\begin{aligned}
\ln \left(E\left(F D I_{i j s} \mid x_{i j}, \alpha_{s}\right)\right) & =\alpha_{s}+\text { South dummy }+\sum_{i=1}^{6} \kappa_{i} \text { Non-Gov. determinants } \neq \text { responses } \\
& \left.+\sum_{i=7}^{12} \kappa_{i} \text { (Non-Gov. determinants } \neq \text { responses } \times \text { South dummy }\right) \\
& +\sum_{i=1}^{17} \lambda_{i} \text { Non-Gov. determinants }=\text { responses } \\
& +\delta_{1} \text { Source governance }+\delta_{2} \text { Destination governance } \\
& \left.+\delta_{3} \text { (Source governance } \times \text { South dummy }\right)+\delta_{4}(\text { Destination governance } \times \text { South dummy })
\end{aligned}
$$

There are three main differences between equation (1) and equation (4). First, the subscript $g$ has disappeared since only a subset of the explanatory variables are allowed to have a distinct impact on S-S FDI and N-S FDI. Second, we now include a South (source country) dummy. Third, this South dummy is interacted both with the non-governance determinants for which we have found a systematically statistical different impact across groups (Non-Gov. determinants $\neq$ responses) and with our governance variables. Other determinants (Non-Gov. determinants $=$ responses) are assumed to have the same impact on both groups of investors and are therefore not interacted with the South dummy. Those FDI determinants to which NS-FDI and SS-FDI appear to be equally sensitive are given in Table 6, while those FDI determinants to which NS-FDI and SS-FDI respond differently are presented in Table 7 and the diverging impacts of

\footnotetext{
${ }^{28}$ We also impose a common overdispersion parameter $\alpha$. Using a generalised NBRM to allow $\alpha$ to differ across groups does not change the results.

${ }^{29}$ Our results hold, albeit logically at a lower significance level, when we include additional interaction terms for the variables that we found to occasionally have a statistically significant different impact on NS-FDI and SS-FDI.
} 
governance variables on NS-FDI and SS-FDI are given in Table 8.

Tables 6 to 8 confirm previous results. The richest developing countries tend to be the largest sources of SS-FDI, and S-MNEs generally invest more in physically and linguistically close destination countries than N-MNEs. Furthermore, they seem to be less deterred by poor macroeconomic performance than their Northern counterparts but, contrary to the latter, do not seem to be influenced by religious similarity. This behaviour fits extremely well with common perceptions of SS-FDI and gives credence both to the evolution stage hypothesis and the resilience advantage hypothesis.

Table 8 provides much stronger statistical evidence than that in the previous section that SS-FDI is far less sensitive than NS-FDI to governance conditions, especially in destination countries. The coefficients on most of the interaction terms are negative, large (in absolute values) and statistically significant, which implies that we can now reject the equality of coefficients across groups. Contrary to NS-FDI, SS-FDI appears to be little attracted by Government Efficiency, Rule of Law or Control of Corruption. It may seem paradoxical that these three governance dimensions are nevertheless among the strongest governance determinants of outward SS-FDI. A possible justification is that the survival and growth of firms in South countries is extremely reliant on their presence, implying that MNEs from these countries have had to develop strategies, that they are able to 'export' abroad, to deal with the relative absence of precisely these three dimensions. Overall, these results contribute to the credibility of the resilience advantage hypothesis.

\subsection{Direct evidence on the resilience advantage}

\subsubsection{The interaction of Source governance with Destination governance}

In the previous section, we found some descriptive evidence that S-MNEs are more likely to emerge and invest in countries characterised by institutional voids than are N-MNEs. The hypothesis underlying these trends is that South firms that have been able to overcome the challenges of operating under poor governance conditions have incorporated these capabilities into a FSA that allows them, in combination with other FSAs, to take advantage investment of opportunities abroad in other risky South countries. Conversely, N-MNEs do not have this resilience advantage, and, in addition, this may hinder the exploitation of some of their other FSAs. This chain of reasoning suggests that more direct evidence on the ability of S-MNEs to turn home institutional disadvantages into a FSA can be obtained by interacting Source (S.) governance with Destination (D.) governance. If the hypothesis that S-MNEs are more able to deal with poor governance abroad as a result of their experience of similar conditions at home is valid, the coefficient on the interaction term should be positive and statistically significant, implying that destination governance matters less in attracting FDI when source governance 
Table 6: Common responses of NS-FDI and SS-FDI

\begin{tabular}{|c|c|c|c|c|c|c|}
\hline Governance & $\begin{array}{l}\text { VA } \\
(1) \\
\end{array}$ & $\begin{array}{l}\text { PS } \\
(2)\end{array}$ & $\begin{array}{l}\text { GE } \\
(3)\end{array}$ & $\begin{array}{l}\text { RQ } \\
(4)\end{array}$ & $\begin{array}{l}\text { RL } \\
\text { (5) }\end{array}$ & $\begin{array}{l}\mathrm{CC} \\
(6)\end{array}$ \\
\hline Source $\ln (\mathrm{GDP})$ & $\begin{array}{l}0.78^{a} \\
(0.04)\end{array}$ & $\begin{array}{l}0.83^{a} \\
(0.04)\end{array}$ & $\begin{array}{l}0.83^{a} \\
(0.04)\end{array}$ & $\begin{array}{l}0.86^{a} \\
(0.04)\end{array}$ & $\begin{array}{l}0.86^{a} \\
(0.04)\end{array}$ & $\begin{array}{l}0.90^{a} \\
(0.04)\end{array}$ \\
\hline Destination $\ln (\mathrm{GDP})$ & $\begin{array}{l}0.77^{a} \\
(0.04)\end{array}$ & $\begin{array}{l}0.74^{a} \\
(0.03)\end{array}$ & $\begin{array}{l}0.71^{a} \\
(0.04)\end{array}$ & $\begin{array}{l}0.72^{a} \\
(0.04)\end{array}$ & $\begin{array}{l}0.73^{a} \\
(0.04)\end{array}$ & $\begin{array}{l}0.75^{a} \\
(0.04)\end{array}$ \\
\hline Destination $\ln ($ GDPPC $)$ & $\begin{array}{c}0.04 \\
(0.06)\end{array}$ & $\begin{array}{c}0.03 \\
(0.06)\end{array}$ & $\begin{array}{l}-0.08 \\
(0.07)\end{array}$ & $\begin{array}{l}-0.05 \\
(0.06)\end{array}$ & $\begin{array}{c}0.05 \\
(0.07)\end{array}$ & $\begin{array}{c}0.01 \\
(0.07)\end{array}$ \\
\hline Source average real GDPPC growth rate & $\begin{array}{l}-0.08^{b} \\
(0.04)\end{array}$ & $\begin{array}{l}-0.08^{b} \\
(0.04)\end{array}$ & $\begin{array}{l}-0.21^{a} \\
(0.05)\end{array}$ & $\begin{array}{l}-0.14^{a} \\
(0.04)\end{array}$ & $\begin{array}{c}-0.14^{a} \\
(0.04)\end{array}$ & $\begin{array}{r}-0.12^{a} \\
(0.04)\end{array}$ \\
\hline Destination average real GDPPC growth rate & $\begin{array}{c}0.02 \\
(0.01)\end{array}$ & $\begin{array}{l}-0.03^{c} \\
(0.01)\end{array}$ & $\begin{array}{c}0.00 \\
(0.01)\end{array}$ & $\begin{array}{c}0.01 \\
(0.01)\end{array}$ & $\begin{array}{c}0.00 \\
(0.01)\end{array}$ & $\begin{array}{c}0.01 \\
(0.01)\end{array}$ \\
\hline Source $\ln$ (inflation) & $\begin{array}{l}-0.34^{a} \\
(0.07)\end{array}$ & $\begin{array}{l}-0.05 \\
(0.06)\end{array}$ & $\begin{array}{l}-0.04 \\
(0.06)\end{array}$ & $\begin{array}{l}-0.19^{a} \\
(0.06)\end{array}$ & $\begin{array}{c}0.06 \\
(0.06)\end{array}$ & $\begin{array}{l}-0.01 \\
(0.06)\end{array}$ \\
\hline Destination $\ln$ (inflation) & $\begin{array}{c}0.04 \\
(0.04)\end{array}$ & $\begin{array}{l}0.19^{a} \\
(0.04)\end{array}$ & $\begin{array}{l}0.17^{a} \\
(0.04)\end{array}$ & $\begin{array}{l}0.22^{a} \\
(0.04)\end{array}$ & $\begin{array}{l}0.13^{a} \\
(0.04)\end{array}$ & $\begin{array}{c}0.14^{a} \\
(0.04)\end{array}$ \\
\hline Destination country landlocked dummy & $\begin{array}{l}-0.34^{a} \\
(0.11)\end{array}$ & $\begin{array}{c}-0.49^{a} \\
(0.12)\end{array}$ & $\begin{array}{c}-0.44^{a} \\
(0.11)\end{array}$ & $\begin{array}{c}-0.44^{a} \\
(0.11)\end{array}$ & $\begin{array}{c}-0.45^{a} \\
(0.11)\end{array}$ & $\begin{array}{c}-0.44^{a} \\
(0.11)\end{array}$ \\
\hline Contiguity dummy & $\begin{array}{c}0.13 \\
(0.21)\end{array}$ & $\begin{array}{c}0.26 \\
(0.21)\end{array}$ & $\begin{array}{c}0.16 \\
(0.20)\end{array}$ & $\begin{array}{c}0.15 \\
(0.20)\end{array}$ & $\begin{array}{c}0.21 \\
(0.22)\end{array}$ & $\begin{array}{c}0.08 \\
(0.21)\end{array}$ \\
\hline Time zone difference & $\begin{array}{l}-0.03 \\
(0.02)\end{array}$ & $\begin{array}{l}-0.05^{b} \\
(0.02)\end{array}$ & $\begin{array}{l}-0.02 \\
(0.02)\end{array}$ & $\begin{array}{l}-0.05^{b} \\
(0.02)\end{array}$ & $\begin{array}{l}-0.03 \\
(0.02)\end{array}$ & $\begin{array}{l}-0.02 \\
(0.02)\end{array}$ \\
\hline Bilateral RTA (BRTA) & $\begin{array}{l}-0.21 \\
(0.23)\end{array}$ & $\begin{array}{l}-0.01 \\
(0.24)\end{array}$ & $\begin{array}{l}-0.61^{b} \\
(0.26)\end{array}$ & $\begin{array}{c}-0.95^{a} \\
(0.24)\end{array}$ & $\begin{array}{l}-0.40 \\
(0.25)\end{array}$ & $\begin{array}{l}-0.39 \\
(0.26)\end{array}$ \\
\hline BRTA with D. in Multilateral RTA (MRTA) & $\begin{array}{l}0.81^{a} \\
(0.30)\end{array}$ & $\begin{array}{l}1.14^{a} \\
(0.30)\end{array}$ & $\begin{array}{l}0.52^{c} \\
(0.29)\end{array}$ & $\begin{array}{c}0.19 \\
(0.30)\end{array}$ & $\begin{array}{l}1.02^{a} \\
(0.32)\end{array}$ & $\begin{array}{l}0.83^{a} \\
(0.31)\end{array}$ \\
\hline D. in MRTA & $\begin{array}{l}0.66^{a} \\
(0.10)\end{array}$ & $\begin{array}{l}0.73^{a} \\
(0.10)\end{array}$ & $\begin{array}{l}0.79^{a} \\
(0.10)\end{array}$ & $\begin{array}{l}0.59^{a} \\
(0.11)\end{array}$ & $\begin{array}{l}0.78^{a} \\
(0.11)\end{array}$ & $\begin{array}{l}0.81^{a} \\
(0.11)\end{array}$ \\
\hline Currency union & $\begin{array}{c}0.67 \\
(0.53)\end{array}$ & $\begin{array}{l}0.83^{c} \\
(0.47)\end{array}$ & $\begin{array}{c}0.58 \\
(0.52)\end{array}$ & $\begin{array}{c}0.67 \\
(0.46)\end{array}$ & $\begin{array}{l}1.01^{b} \\
(0.51)\end{array}$ & $\begin{array}{c}0.75 \\
(0.48)\end{array}$ \\
\hline $\ln$ (number of migrants from S. in D.) & $\begin{array}{l}0.12^{a} \\
(0.02)\end{array}$ & $\begin{array}{l}0.12^{a} \\
(0.02)\end{array}$ & $\begin{array}{l}0.13^{a} \\
(0.02)\end{array}$ & $\begin{array}{l}0.10^{a} \\
(0.02)\end{array}$ & $\begin{array}{l}0.13^{a} \\
(0.02)\end{array}$ & $\begin{array}{l}0.13^{a} \\
(0.02)\end{array}$ \\
\hline $\ln$ (number of migrants from D. in S.) & $\begin{array}{l}0.07^{a} \\
(0.02)\end{array}$ & $\begin{array}{l}0.11^{a} \\
(0.02)\end{array}$ & $\begin{array}{l}0.05^{a} \\
(0.02)\end{array}$ & $\begin{array}{l}0.07^{a} \\
(0.02)\end{array}$ & $\begin{array}{l}0.07^{a} \\
(0.02)\end{array}$ & $\begin{array}{l}0.06^{a} \\
(0.02)\end{array}$ \\
\hline $\ln ($ genetic distance $)$ & $\begin{array}{l}0.16^{a} \\
(0.05)\end{array}$ & $\begin{array}{l}0.15^{a} \\
(0.05)\end{array}$ & $\begin{array}{l}0.14^{a} \\
(0.05)\end{array}$ & $\begin{array}{l}0.10^{b} \\
(0.05)\end{array}$ & $\begin{array}{l}0.14^{a} \\
(0.05)\end{array}$ & $\begin{array}{l}0.16^{a} \\
(0.05)\end{array}$ \\
\hline
\end{tabular}

Notes: ${ }^{a} \mathrm{p}<0.01{ }^{b} \mathrm{p}<0.05{ }^{c} \mathrm{p}<0.10$. Cluster-robust standard errors in parentheses. VA: Voice and Accountability; PS: Political Stability; GE: Government Effectiveness; RQ; Regulatory Quality; RL: Rule of Law; CC: Control of Corruption. S: Source; D: Destination. 
Table 7: Systematically diverging responses of NS-FDI and SS-FDI

\begin{tabular}{|c|c|c|c|c|c|c|}
\hline VARIABLES & (1) & (2) & (3) & (4) & (5) & (6) \\
\hline Source $\ln (\mathrm{GDPPC})$ & $\begin{array}{c}0.36 \\
(0.26)\end{array}$ & $\begin{array}{c}-0.57^{a} \\
(0.21)\end{array}$ & $\begin{array}{c}-1.23^{a} \\
(0.28)\end{array}$ & $\begin{array}{l}-0.38 \\
(0.25)\end{array}$ & $\begin{array}{c}-1.46^{a} \\
(0.27)\end{array}$ & $\begin{array}{c}-1.09^{a} \\
(0.26)\end{array}$ \\
\hline Source $\ln ($ GDPPC) X South dummy & $\begin{array}{c}0.30 \\
(0.27)\end{array}$ & $\begin{array}{l}1.44^{a} \\
(0.25)\end{array}$ & $\begin{array}{c}1.29^{a} \\
(0.29)\end{array}$ & $\begin{array}{l}0.71^{a} \\
(0.27)\end{array}$ & $\begin{array}{l}1.98^{a} \\
(0.29)\end{array}$ & $\begin{array}{l}1.56^{a} \\
(0.28)\end{array}$ \\
\hline $\ln$ (bilateral distance) & $\begin{array}{l}-0.69^{a} \\
(0.12)\end{array}$ & $\begin{array}{l}-0.37^{a} \\
(0.11)\end{array}$ & $\begin{array}{c}-0.74^{a} \\
(0.12)\end{array}$ & $\begin{array}{c}-0.66^{a} \\
(0.13)\end{array}$ & $\begin{array}{l}-0.66^{a} \\
(0.11)\end{array}$ & $\begin{array}{l}-0.72^{a} \\
(0.12)\end{array}$ \\
\hline $\ln$ (bilateral distance) X South dummy & $\begin{array}{l}-0.39^{a} \\
(0.14)\end{array}$ & $\begin{array}{l}-0.54^{a} \\
(0.14)\end{array}$ & $\begin{array}{c}-0.35^{b} \\
(0.14)\end{array}$ & $\begin{array}{c}-0.36^{b} \\
(0.15)\end{array}$ & $\begin{array}{c}-0.37^{a} \\
(0.14)\end{array}$ & $\begin{array}{c}-0.41^{a} \\
(0.14)\end{array}$ \\
\hline MRTA & $\begin{array}{c}0.44 \\
(0.51)\end{array}$ & $\begin{array}{l}-0.09 \\
(0.46)\end{array}$ & $\begin{array}{c}0.06 \\
(0.36)\end{array}$ & $\begin{array}{l}-0.69 \\
(0.48)\end{array}$ & $\begin{array}{c}0.34 \\
(0.35)\end{array}$ & $\begin{array}{c}0.26 \\
(0.33)\end{array}$ \\
\hline MRTA X South dummy & $\begin{array}{l}0.97^{c} \\
(0.54)\end{array}$ & $\begin{array}{l}1.46^{a} \\
(0.49)\end{array}$ & $\begin{array}{c}1.63^{a} \\
(0.40)\end{array}$ & $\begin{array}{l}2.22^{a} \\
(0.50)\end{array}$ & $\begin{array}{l}1.36^{a} \\
(0.39)\end{array}$ & $\begin{array}{l}1.39^{a} \\
(0.37)\end{array}$ \\
\hline Colonial relationship dummy & $\begin{array}{l}1.06^{a} \\
(0.23)\end{array}$ & $\begin{array}{l}1.03^{a} \\
(0.21)\end{array}$ & $\begin{array}{l}0.95^{a} \\
(0.24)\end{array}$ & $\begin{array}{l}1.28^{a} \\
(0.27)\end{array}$ & $\begin{array}{l}0.88^{a} \\
(0.23)\end{array}$ & $\begin{array}{l}0.95^{a} \\
(0.23)\end{array}$ \\
\hline Colonial relationship X South dummy & $\begin{array}{l}-1.27^{b} \\
(0.55)\end{array}$ & $\begin{array}{l}-1.79^{a} \\
(0.57)\end{array}$ & $\begin{array}{c}-1.30^{a} \\
(0.47)\end{array}$ & $\begin{array}{c}-1.38^{a} \\
(0.50)\end{array}$ & $\begin{array}{r}-1.42^{a} \\
(0.54)\end{array}$ & $\begin{array}{r}-1.43^{a} \\
(0.51)\end{array}$ \\
\hline Common language dummy & $\begin{array}{l}0.36^{c} \\
(0.21)\end{array}$ & $\begin{array}{l}0.38^{b} \\
(0.17)\end{array}$ & $\begin{array}{l}0.36^{c} \\
(0.20)\end{array}$ & $\begin{array}{c}0.18 \\
(0.20)\end{array}$ & $\begin{array}{l}0.38^{c} \\
(0.21)\end{array}$ & $\begin{array}{c}0.32 \\
(0.20)\end{array}$ \\
\hline Common language $\mathrm{X}$ South dummy & $\begin{array}{l}0.64^{b} \\
(0.29)\end{array}$ & $\begin{array}{l}0.85^{a} \\
(0.27)\end{array}$ & $\begin{array}{c}0.61^{b} \\
(0.28)\end{array}$ & $\begin{array}{l}0.83^{a} \\
(0.28)\end{array}$ & $\begin{array}{l}0.82^{a} \\
(0.29)\end{array}$ & $\begin{array}{l}0.80^{a} \\
(0.29)\end{array}$ \\
\hline Religious similarity & $\begin{array}{l}0.81^{a} \\
(0.21)\end{array}$ & $\begin{array}{l}0.49^{b} \\
(0.20)\end{array}$ & $\begin{array}{c}1.26^{a} \\
(0.23)\end{array}$ & $\begin{array}{l}0.90^{a} \\
(0.22)\end{array}$ & $\begin{array}{l}1.27^{a} \\
(0.22)\end{array}$ & $\begin{array}{l}1.31^{a} \\
(0.23)\end{array}$ \\
\hline Religious similarity X South dummy & $\begin{array}{l}-0.89^{b} \\
(0.39)\end{array}$ & $\begin{array}{l}-0.93^{b} \\
(0.39)\end{array}$ & $\begin{array}{c}-1.08^{a} \\
(0.38)\end{array}$ & $\begin{array}{c}-1.21^{a} \\
(0.38)\end{array}$ & $\begin{array}{l}-1.36^{a} \\
(0.41)\end{array}$ & $\begin{array}{l}-1.53^{a} \\
(0.40)\end{array}$ \\
\hline South source country dummy & $\begin{array}{c}0.92 \\
(3.11)\end{array}$ & $\begin{array}{c}-10.29^{a} \\
(2.85)\end{array}$ & $\begin{array}{l}-9.88^{a} \\
(3.24)\end{array}$ & $\begin{array}{l}-3.85 \\
(3.07)\end{array}$ & $\begin{array}{c}-15.67^{a} \\
(3.25)\end{array}$ & $\begin{array}{r}-11.88^{a} \\
(3.21)\end{array}$ \\
\hline Observations & 46,332 & 46,332 & 46,332 & 46,332 & 46,332 & 46,332 \\
\hline
\end{tabular}


Table 8: Diverging responses of NS-FDI and SS-FDI to governance

\begin{tabular}{|c|c|c|c|c|c|c|}
\hline Governance & $\begin{array}{l}\text { VA } \\
(1) \\
\end{array}$ & $\begin{array}{l}\text { PS } \\
(2) \\
\end{array}$ & $\begin{array}{l}\text { GE } \\
(3) \\
\end{array}$ & $\begin{array}{l}\text { RQ } \\
(4) \\
\end{array}$ & $\begin{array}{l}\mathrm{RL} \\
(5) \\
\end{array}$ & $\begin{array}{l}\mathrm{CC} \\
(6) \\
\end{array}$ \\
\hline Source voice and accountability & $\begin{array}{l}1.62^{a} \\
(0.14)\end{array}$ & & & & & \\
\hline Destination voice and accountability & $\begin{array}{l}0.57^{a} \\
(0.06)\end{array}$ & & & & & \\
\hline Source political stability & & $\begin{array}{l}1.13^{a} \\
(0.20)\end{array}$ & & & & \\
\hline Destination political stability & & $\begin{array}{l}0.65^{a} \\
(0.07)\end{array}$ & & & & \\
\hline Source government effectiveness & & & $\begin{array}{l}1.87^{a} \\
(0.12)\end{array}$ & & & \\
\hline Destination government effectiveness & & & $\begin{array}{c}0.98^{a} \\
(0.10)\end{array}$ & & & \\
\hline Source regulatory quality & & & & $\begin{array}{c}1.95^{a} \\
(0.13)\end{array}$ & & \\
\hline Destination regulatory quality & & & & $\begin{array}{c}1.08^{a} \\
(0.09)\end{array}$ & & \\
\hline Source rule of law & & & & & $\begin{array}{c}2.33^{a} \\
(0.16)\end{array}$ & \\
\hline Destination rule of law & & & & & $\begin{array}{l}0.55^{a} \\
(0.08)\end{array}$ & \\
\hline Source control of corruption & & & & & & $\begin{array}{l}1.51^{a} \\
(0.09)\end{array}$ \\
\hline Destination control of corruption & & & & & & $\begin{array}{l}0.67^{a} \\
(0.09)\end{array}$ \\
\hline Source governance X South dummy & $\begin{array}{c}-0.73^{a} \\
(0.17)\end{array}$ & $\begin{array}{c}-0.77^{a} \\
(0.23)\end{array}$ & $\begin{array}{c}0.05 \\
(0.19)\end{array}$ & $\begin{array}{c}-0.48^{a} \\
(0.18)\end{array}$ & $\begin{array}{c}-1.12^{a} \\
(0.20)\end{array}$ & $\begin{array}{l}-0.28^{c} \\
(0.17)\end{array}$ \\
\hline Destination governance $\mathrm{X}$ South dummy & $\begin{array}{l}-0.20^{c} \\
(0.12)\end{array}$ & $\begin{array}{l}-0.26^{b} \\
(0.11)\end{array}$ & $\begin{array}{c}-0.75^{a} \\
(0.15)\end{array}$ & $\begin{array}{c}-0.54^{a} \\
(0.15)\end{array}$ & $\begin{array}{c}-0.58^{a} \\
(0.14)\end{array}$ & $\begin{array}{l}-0.53^{a} \\
(0.15)\end{array}$ \\
\hline Implied South source governance coeff. & $\begin{array}{c}0.90^{a} \\
(0.10)\end{array}$ & $\begin{array}{c}0.35^{b} \\
(0.16)\end{array}$ & $\begin{array}{c}1.92^{a} \\
(0.20)\end{array}$ & $\begin{array}{c}1.47^{a} \\
(0.14)\end{array}$ & $\begin{array}{c}1.20^{a} \\
(0.16)\end{array}$ & $\begin{array}{l}1.23^{a} \\
(0.15)\end{array}$ \\
\hline Implied South destination governance coeff. & $\begin{array}{c}0.37^{a} \\
(0.10)\end{array}$ & $\begin{array}{l}0.38^{a} \\
(0.11)\end{array}$ & $\begin{array}{c}0.23 \\
(0.15)\end{array}$ & $\begin{array}{l}0.54^{a} \\
(0.14)\end{array}$ & $\begin{array}{c}-0.04 \\
(0.14)\end{array}$ & $\begin{array}{c}0.14 \\
(0.16)\end{array}$ \\
\hline Observations & 46,332 & 46,332 & 46,332 & 46,332 & 46,332 & 46,332 \\
\hline
\end{tabular}


is deficient. ${ }^{30}$ We explore this issue in Table 9. For ease of comparison with previous results, we have rescaled the destination governance variables by subtracting their mean values in North countries.

Table 9 provides strong direct evidence that S-MNEs have turned their experience of dealing with poor institutional quality at home into a transferable FSA, as the coefficient on the interaction term is positive and statistically significant. The "fit" between our descriptive evidence and our causal evidence can be assessed by comparing the coefficients on the ('North') destination governance variables in Table 8 and Table 9. Assuming that the unconditional coefficients for each group of investors are (weighted) averages of the effects conditional on source governance, and remembering the re-scaling of the destination variables, we should find that the coefficients on the latter variables do not differ much if the causal hypothesis is true. That is precisely what we observe, strengthening our interpretation in the diverging sensitivities of NS-FDI and SS-FDI to institutional risk.

Figure 3 provides a graphical interpretation of the results, as we plot the impact of a one point improvement in destination governance on the expected number of distinct MNEs in a given host country, conditional on the governance of the source country, i.e. $\theta_{2} \times$ D. governance $+\theta_{3} \times$ S. governance, in relation to equation (2). It can be seen that exposure to poor governance at home makes MNEs less sensitive to poor governance abroad. For instance, taking the median value of governance for FDI-active (at least one affiliate abroad) South and North countries as reference points, a one point increase in Regulatory Quality would lead to a statistically significant increase in the expected number of S-MNEs of $e^{0.61}-1=84 \%$, an effect about half that of the estimated impact on N-MNEs (166\%). Using the same reference points, we can observe that the location of S-MNEs abroad does not seem to be deterred, at least in statistical terms, by the quality of Government Efficiency, Rule of Law and Control of Corruption. In contrast, all governance dimensions matter for N-MNEs.

An alternative, but not necessarily competing, explanation for our results is that the location choices of some foreign investors are directly constrained by the policies adopted by their source countries. ${ }^{31}$ For instance, previous research has tried to determine whether laws against the bribery of public officials have influenced FDI. The results are mixed. Wei (2000) finds no impact of the 1977 U.S. Foreign Corrupt Practices Act on outward U.S. FDI whereas Cuervo-

\footnotetext{
${ }^{30}$ An alternative explanation could be that NS-FDI and SS-FDI differ in their nature, the former being more of the vertical type while the the latter would be more of the horizontal type. This could explain their different sensitivity to destination governance as Desbordes (2007) has shown that MNEs in vertically integrated industries are unlikely to locate their foreign activities in risky countries in order to minimize the "relational costs" potentially generated by the geographic separation of various production stages. However, the facts that NS-FDI, in comparison to SS-FDI, (i) appears to be more sensitive to the size and growth rate of the destination country's market size (Table 2), (ii) is less negatively influenced by geographic distance (Table 3), (iii) is positively related to genetic distance, which may be a proxy for transport costs (Table 4), (iv) appears to be less influenced by 'Development Similarity', which may proxy for differences in labour costs (Table 11), suggest that there is no reason to believe that NS-FDI is more vertical than SS-FDI.

${ }^{31} \mathrm{We}$ would like to thank the referee for suggesting this possibility.
} 
Table 9: Testing the resilience advantage

\begin{tabular}{llllllll}
\hline & $(1)$ & $(2)$ & $(3)$ & $(4)$ & $(5)$ & $(6)$ & $(7)$ \\
Governance & VA & PS & GE & RQ & RL & CC & CC \\
\hline
\end{tabular}

Source voice and accountability

Source political stability

Source government effectiveness

Source regulatory quality

Source rule of law

Source control of corruption

Source governance X South dummy

Destination voice and accountability

Destination political stability

Destination government effectiveness

Destination regulatory quality

Destination rule of law

Destination control of corruption

S. governance X D. governance

Source OECD Anti Bribery Convention

OECD Anti Bribery Convention X D. CC $1.71^{a}$

(0.14)

$$
1.19^{a}
$$

$1.95^{a}$

(0.12)

$2.00^{a}$

(0.13)

$2.43^{a}$

(0.16)

$1.60^{a} \quad 1.49^{a}$

(0.10) (0.10)

$\begin{array}{lllllll}-0.73^{a} & -0.76^{a} & 0.08 & -0.47^{b} & -1.10^{a} & -0.27 & -0.30^{c}\end{array}$

$\begin{array}{lllllll}(0.17) & (0.24) & (0.20) & (0.18) & (0.20) & (0.17) & (0.17)\end{array}$

$0.54^{a}$

(0.06)

$0.62^{a}$

(0.06)

$0.86^{a}$

(0.10)

$0.98^{a}$

(0.09)

$0.47^{a}$

$(0.08)$

$0.59^{a} \quad 0.46^{b}$

(0.09) (0.19)

$\begin{array}{lllllll}0.20^{a} & 0.16^{b} & 0.40^{a} & 0.31^{a} & 0.28^{a} & 0.23^{a} & 0.19^{b}\end{array}$

$\begin{array}{lllllll}(0.06) & (0.08) & (0.07) & (0.09) & (0.07) & (0.07) & (0.09)\end{array}$

$0.40^{b}$

(0.16)

0.15

$(0.20)$

Observations

$\begin{array}{lllllll}46,332 & 46,332 & 46,332 & 46,332 & 46,332 & 46,332 & 46,332\end{array}$

Notes: ${ }^{a} \mathrm{p}<0.01{ }^{b} \mathrm{p}<0.05{ }^{c} \mathrm{p}<0.10$. Cluster-robust standard errors in parentheses. VA: Voice and Accountability; PS: Political

Stability; GE: Government Effectiveness; RQ; Regulatory Quality; RL: Rule of Law; CC: Control of Corruption. S: Source; D:

Destination. All regressions include the full set of explanatory variables that we have previously used in our semi-constrained model (see equation 4). Their coefficients are not reported to save space. 
Figure 3: Effect of Destination governance conditional on Source governance
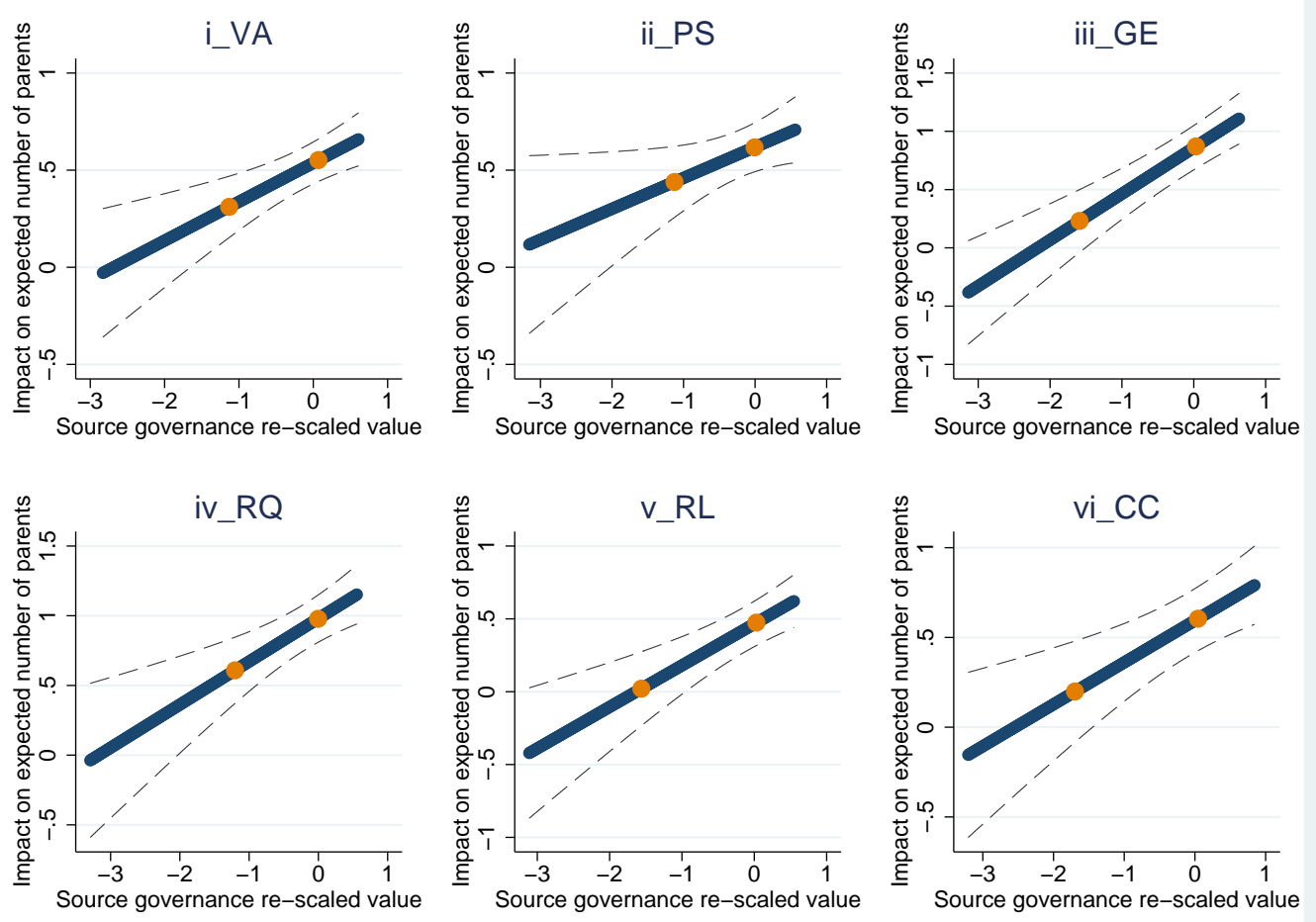

Notes: Dashed lines correspond to a 95\% confidence interval. Dots represent the median value of governance for FDI-active South and North countries.

Cazurra (2006) show that signatories of the 1999 OECD Convention on Combating Bribery of Foreign Public Officials in International Business Transactions invest less in relatively corrupt countries than non-signatories. Hence, our regression in column (6) of Table 9 may suffer from an omitted variable bias, in the sense that we have not taken into account the eventuality that whatever the corruption level in their source country, some foreign investors may find it difficult to invest in corrupt destination countries without breaking anti-bribery laws in their home countries. We investigate this possibility in column (7) of Table 9 by interacting an OECD Anti Bribery Convention dummy with destination CC. The coefficient on this interaction term is positive, but not statistically significant, while size and statistical significance of the coefficient on the interaction between source and destination governance appear little affected in comparison to column (6). Overall, we find little evidence that anti-bribery laws influence the location choice of OECD investors. ${ }^{32}$

In Table 10, we investigate whether there is direct mapping between source and destination governance, in the sense that the resilience advantage of S-MNEs is specific to a given governance dimension. That does not appear the case since interacting a given destination governance dimension with a different source governance dimension generates positive and statistically significant coefficients on the interaction terms with very similar magnitudes. A lack of Government

\footnotetext{
${ }^{32}$ This result is in agreement with recent Transparency International Bribe Payers Index surveys, available at http: //www. transparency . org/policy_research/surveys_indices/bpi, which report that OECD-based MNEs still routinely pay bribes abroad to gain a business advantage.
} 
Table 10: Mapping between source and destination governance

\begin{tabular}{|c|c|c|c|c|c|c|}
\hline Governance & $\begin{array}{l}\text { VA } \\
(1) \\
\end{array}$ & $\begin{array}{l}\text { PS } \\
(2)\end{array}$ & $\begin{array}{l}\text { GE } \\
(3)\end{array}$ & $\begin{array}{l}\text { RQ } \\
(4)\end{array}$ & $\begin{array}{l}\text { RL } \\
(5)\end{array}$ & $\begin{array}{l}\mathrm{CC} \\
(6) \\
\end{array}$ \\
\hline Destination Voice and Accountability & $\begin{array}{l}0.54^{a} \\
(0.06)\end{array}$ & $\begin{array}{c}0.58^{a} \\
(0.06)\end{array}$ & $\begin{array}{c}0.56^{a} \\
(0.06)\end{array}$ & $\begin{array}{c}0.60^{a} \\
(0.06)\end{array}$ & $\begin{array}{c}0.57^{a} \\
(0.06)\end{array}$ & $\begin{array}{l}0.57^{a} \\
(0.06)\end{array}$ \\
\hline S. governance X D. governance & $\begin{array}{l}0.20^{a} \\
(0.06)\end{array}$ & $\begin{array}{l}0.15^{c} \\
(0.08)\end{array}$ & $\begin{array}{l}0.17^{a} \\
(0.06)\end{array}$ & $\begin{array}{l}0.23^{a} \\
(0.07)\end{array}$ & $\begin{array}{l}0.10^{c} \\
(0.06)\end{array}$ & $\begin{array}{l}0.12^{b} \\
(0.05)\end{array}$ \\
\hline Destination Political Stability & $\begin{array}{c}0.58^{a} \\
(0.06)\end{array}$ & $\begin{array}{l}0.62^{a} \\
(0.06)\end{array}$ & $\begin{array}{l}0.61^{a} \\
(0.06)\end{array}$ & $\begin{array}{c}0.63^{a} \\
(0.06)\end{array}$ & $\begin{array}{l}0.65^{a} \\
(0.06)\end{array}$ & $\begin{array}{l}0.65^{a} \\
(0.06)\end{array}$ \\
\hline S. governance X D. governance & $\begin{array}{l}0.22^{a} \\
(0.07)\end{array}$ & $\begin{array}{c}0.16^{b} \\
(0.08)\end{array}$ & $\begin{array}{c}0.17^{a} \\
(0.06)\end{array}$ & $\begin{array}{l}0.24^{a} \\
(0.08)\end{array}$ & $\begin{array}{l}0.15^{b} \\
(0.06)\end{array}$ & $\begin{array}{l}0.14^{a} \\
(0.05)\end{array}$ \\
\hline Destination Government Effectiveness & $\begin{array}{c}0.77^{a} \\
(0.10)\end{array}$ & $\begin{array}{l}0.80^{a} \\
(0.10)\end{array}$ & $\begin{array}{c}0.86^{a} \\
(0.10)\end{array}$ & $\begin{array}{c}0.90^{a} \\
(0.10)\end{array}$ & $\begin{array}{l}0.89^{a} \\
(0.10)\end{array}$ & $\begin{array}{l}0.89^{a} \\
(0.10)\end{array}$ \\
\hline S. governance X D. governance & $\begin{array}{l}0.38^{a} \\
(0.08)\end{array}$ & $\begin{array}{l}0.34^{a} \\
(0.09)\end{array}$ & $\begin{array}{c}0.40^{a} \\
(0.07)\end{array}$ & $\begin{array}{l}0.44^{a} \\
(0.09)\end{array}$ & $\begin{array}{l}0.35^{a} \\
(0.07)\end{array}$ & $\begin{array}{l}0.30^{a} \\
(0.06)\end{array}$ \\
\hline Destination Regulatory Quality & $\begin{array}{c}0.89^{a} \\
(0.08)\end{array}$ & $\begin{array}{l}0.94^{a} \\
(0.09)\end{array}$ & $\begin{array}{l}0.94^{a} \\
(0.08)\end{array}$ & $\begin{array}{c}0.98^{a} \\
(0.09)\end{array}$ & $\begin{array}{l}0.97^{a} \\
(0.09)\end{array}$ & $\begin{array}{l}0.96^{a} \\
(0.09)\end{array}$ \\
\hline S. governance X D. governance & $0.27^{a}$ & $0.23^{a}$ & $0.28^{a}$ & $0.31^{a}$ & $0.22^{a}$ & $0.20^{a}$ \\
\hline Destination Rule of Law & $\begin{array}{l}0.38^{a} \\
(0.08)\end{array}$ & $\begin{array}{c}0.37^{a} \\
(0.08)\end{array}$ & $\begin{array}{l}0.44^{a} \\
(0.08)\end{array}$ & $\begin{array}{c}0.46^{a} \\
(0.08)\end{array}$ & $\begin{array}{l}0.47^{a} \\
(0.08)\end{array}$ & $\begin{array}{l}0.46^{a} \\
(0.08)\end{array}$ \\
\hline S. governance X D. governance & $\begin{array}{l}0.32^{a} \\
(0.08)\end{array}$ & $\begin{array}{c}0.28^{a} \\
(0.09)\end{array}$ & $\begin{array}{c}0.33^{a} \\
(0.07)\end{array}$ & $\begin{array}{c}0.36^{a} \\
(0.09)\end{array}$ & $\begin{array}{l}0.28^{a} \\
(0.07)\end{array}$ & $\begin{array}{l}0.27^{a} \\
(0.06)\end{array}$ \\
\hline Destination Control of Corruption & $\begin{array}{c}0.49^{a} \\
(0.09)\end{array}$ & $\begin{array}{c}0.50^{a} \\
(0.09)\end{array}$ & $\begin{array}{c}0.58^{a} \\
(0.09)\end{array}$ & $\begin{array}{c}0.59^{a} \\
(0.09)\end{array}$ & $\begin{array}{l}0.60^{a} \\
(0.09)\end{array}$ & $\begin{array}{l}0.59^{a} \\
(0.09)\end{array}$ \\
\hline S. governance X D. governance & $\begin{array}{l}0.30^{a} \\
(0.09)\end{array}$ & $\begin{array}{c}0.24^{b} \\
(0.10)\end{array}$ & $\begin{array}{c}0.30^{a} \\
(0.07)\end{array}$ & $\begin{array}{l}0.32^{a} \\
(0.10)\end{array}$ & $\begin{array}{l}0.24^{a} \\
(0.08)\end{array}$ & $\begin{array}{l}0.23^{a} \\
(0.07)\end{array}$ \\
\hline Observations & 46,332 & 46,332 & 46,332 & 46,332 & 46,332 & 46,332 \\
\hline
\end{tabular}


Effectiveness and Regulatory Quality seems to contribute the most to the formation of the resilience advantage, and, even though previous results did not suggest this was necessarily the case, the effects of other governance dimensions in Table 10 are likely to be driven mostly by their correlations with these two governance attributes.

Overall, this section has presented some direct evidence that the factual observation that S-MNEs tend to be less sensitive to destination governance than N-MNEs can be explained by the resilience advantage that they have acquired in their home country. In the next section, we run a series of robustness checks.

\subsubsection{Robustness checks}

In panel A of Table 11, we investigate whether removing China, the largest recipient of South-South FDI, makes a difference to our results. Given the mediocre quality of Chinese governance, it is possible that the presence of this country in our sample diminishes the strength of the resilience effect. Next, in panel B, we remove FDI in the primary sector from the sample. Even though we have observed that NS-FDI and SS-FDI tend to have the same sectoral repartition (Table 2), our typology is extremely coarse and may obscure the fact that S-MNEs are more likely to invest in subsoil natural resources to fuel their economic growth than are N-MNEs. As is well known, energy-abundance in South countries frequently coincides with poor governance (Van der Ploeg, 2011). In that case, our interaction term may suffer from an upward aggregation bias. In panel $\mathrm{C}$, in order to reduce the risk that the interaction of the public governance variables picks up any unobserved effects related to the proximity of economic development of a country-pair, e.g. similarity of customers' tastes, we introduce the similarity index proposed by Buch, Kleinert, Lipponer, and Toubal (2005). It is calculated as $S_{s d}=1-\frac{a b s\left(G D P P C_{d}-G D P P C_{s}\right)}{\max \left(G D P P C_{d}, G D P P C_{s}\right)}$ and ranges between 0 (very dissimilar) and 1 (very similar). Finally, in panel D, we investigate whether the fact that we only have majority-owned foreign affiliates (MOFAs) in our sample can explain why we observe more S-MNEs in risky countries than N-MNEs. Hypothetically, if N-MNEs have greater technological intangible assets than S-MNEs they will be less likely to invest in poor-governance countries, and, if investment takes place, they will probably have a controlling equity stake in the foreign affiliate in order to avoid any technology leakage (Smarzynska and Wei, 2000). On the other hand, S-MNEs will be more present in poor-governance countries, and will be more likely than N-MNEs to have minority equity in the foreign affiliate as governance increases. From that technological-orientated perspective, better governance would thus lead to an increase in the occurrence of North MOFAs and a fall in the number of South MOFAs, resulting in an overestimation of the resilience effect. We test for the possibility that North and S-MNEs differ in the technological intensity of their FSAs by including as additional regressor the share of U.S. foreign affiliates that are majority-owned in a given destination country and its interaction with the South dummy; 
U.S. investors supposedly operate at the technology frontier and data on their operations are easily available. A negative and statistically significant coefficient on the share of U.S. MOFAs would be consistent with the idea that N-MNEs share the same concern as U.S. investors about the potential erosion of their FSAs because they operate on the same technological level. Conversely, a positive and statistically significant coefficient on the interaction term would suggest that S-MNEs are less concerned about this erosion risk than N-MNEs because their FSAs are less technology-intensive. Data come from the 1994 Benchmark Survey of U.S. Direct Investment Abroad (Mataloni and Fahim-Nader, 1996). We chose this survey because the reporting threshold ( 3 \$ million) is much lower than in other surveys (7-10 \$million). ${ }^{33}$

Table 11 shows that our key results withstand all our various robustness checks. Size and statistical significance of the governance variables and their interaction terms do not appreciably change when removing China or FDI in the primary sector from the sample, or when we include the (not statistically significant) similarity variable. ${ }^{34}$ Panel D of Table 11 provides some mixed evidence on potential differences in the technological intensity of the FSAs of North and S-MNEs. The coefficient on the share of U.S. MOFAs is negative but not statistically significant in half of the regressions, suggesting that it tends to pick up some negative attributes of a destination country's governance not proxied by some of the governance dimensions, or that the technological intensity of North MNEs is heterogenous and not necessarily in line with U.S. MNEs' technology. In the same vein, even though the coefficient on the interaction term tends to be positive, it loses significance when the coefficient on the share of U.S. MOFAs also loses significance, suggesting that the interaction term reproduces the resilience advantage. Overall, there is little evidence that N-MNEs have systematically greater technology than S-MNEs and therefore, it is unlikely that our results are affected by distinct patterns in the entry mode of the two groups of investors.

We conclude this section by briefly discussing the issue of simultaneity. In our robustness checks, we have mainly dealt with the possibility that we had omitted some confounding variables and we have found little evidence that this was the case. Nevertheless, it could be argued that a simultaneity bias may still be present. For instance, it could be envisaged that greater presence in the destination country allows MNEs to accumulate the experience to deal with the institutional voids that they recurrently face, and possibly share it with other MNEs. Alternatively, when numerous enough, foreign investors may successfully lobby the government for a more favourable business environment. To the extent that this reverse causality channel exists, the use of bilateral FDI data mitigates its effect, which is clearly not strong enough to

\footnotetext{
${ }^{33}$ In Table 11, panel D, we lose some observations as data on the investment of U.S. MNEs in some destination countries are not disclosed for confidentiality reasons.

${ }^{34}$ In unreported regressions, we also verified that our results were robust to the inclusion of regional dummies and to the joint inclusion of source and destination country dummies.
} 
Table 11: Robustness checks

\begin{tabular}{|c|c|c|c|c|c|c|}
\hline Governance & $\begin{array}{l}\text { VA } \\
(1) \\
\end{array}$ & $\begin{array}{l}\text { PS } \\
(2) \\
\end{array}$ & $\begin{array}{l}\text { GE } \\
(3) \\
\end{array}$ & $\begin{array}{c}\text { RQ } \\
(4)\end{array}$ & $\begin{array}{l}\text { RL } \\
(5) \\
\end{array}$ & $\begin{array}{l}\mathrm{CC} \\
(6) \\
\end{array}$ \\
\hline & \multicolumn{6}{|c|}{ A: Without China } \\
\hline \multirow[t]{2}{*}{ Destination governance } & $0.71^{a}$ & $0.54^{a}$ & $0.92^{a}$ & $1.02^{a}$ & $0.55^{a}$ & $0.58^{a}$ \\
\hline & $(0.05)$ & $(0.07)$ & $(0.10)$ & $(0.08)$ & $(0.08)$ & $(0.09)$ \\
\hline \multirow[t]{2}{*}{ S. governance X D. governance } & $0.27^{a}$ & $0.16^{b}$ & $0.39^{a}$ & $0.32^{a}$ & $0.29^{a}$ & $0.23^{a}$ \\
\hline & $(0.06)$ & $(0.08)$ & $(0.07)$ & $(0.09)$ & $(0.07)$ & $(0.07)$ \\
\hline \multirow[t]{2}{*}{ Observations } & 45,903 & 45,903 & 45,903 & 45,903 & 45,903 & 45,903 \\
\hline & \multicolumn{6}{|c|}{ B: Without primary sector } \\
\hline \multirow[t]{2}{*}{ Destination governance } & $0.56^{a}$ & $0.65^{a}$ & $0.90^{a}$ & $1.02^{a}$ & $0.51^{a}$ & $0.62^{a}$ \\
\hline & $(0.06)$ & $(0.07)$ & $(0.10)$ & $(0.09)$ & $(0.09)$ & $(0.10)$ \\
\hline \multirow[t]{2}{*}{ S. governance X D. governance } & $0.22^{a}$ & $0.16^{b}$ & $0.42^{a}$ & $0.34^{a}$ & $0.30^{a}$ & $0.25^{a}$ \\
\hline & $(0.06)$ & $(0.08)$ & $(0.07)$ & $(0.09)$ & $(0.08)$ & $(0.07)$ \\
\hline \multirow[t]{2}{*}{ Observations } & 30,888 & 30,888 & 30,888 & 30,888 & 30,888 & 30,888 \\
\hline & \multicolumn{6}{|c|}{ C: Development similarity } \\
\hline \multirow[t]{2}{*}{ Destination voice and accountability } & $0.54^{a}$ & $0.63^{a}$ & $0.87^{a}$ & $0.98^{a}$ & $0.46^{a}$ & $0.60^{a}$ \\
\hline & $(0.06)$ & $(0.07)$ & $(0.10)$ & $(0.09)$ & $(0.08)$ & $(0.09)$ \\
\hline \multirow[t]{2}{*}{ S. governance X D. governance } & $0.20^{a}$ & $0.17^{b}$ & $0.41^{a}$ & $0.31^{a}$ & $0.28^{a}$ & $0.24^{a}$ \\
\hline & $(0.06)$ & $(0.08)$ & $(0.07)$ & $(0.09)$ & $(0.07)$ & $(0.07)$ \\
\hline \multirow[t]{2}{*}{ Development similarity } & -0.01 & -0.20 & -0.22 & -0.15 & 0.03 & -0.07 \\
\hline & $(0.25)$ & $(0.28)$ & $(0.26)$ & $(0.27)$ & $(0.28)$ & $(0.27)$ \\
\hline \multirow[t]{2}{*}{ Observations } & 46,332 & 46,332 & 46,332 & 46,332 & 46,332 & 46,332 \\
\hline & \multicolumn{6}{|c|}{ D: Technological differences in FSAs } \\
\hline \multirow[t]{2}{*}{ Destination voice and accountability } & $0.48^{a}$ & $0.61^{a}$ & $0.80^{a}$ & $0.97^{a}$ & $0.36^{a}$ & $0.56^{a}$ \\
\hline & $(0.06)$ & $(0.07)$ & $(0.10)$ & $(0.09)$ & $(0.08)$ & $(0.09)$ \\
\hline \multirow[t]{2}{*}{ S. governance X D. governance } & $0.19^{a}$ & $0.17^{b}$ & $0.41^{a}$ & $0.33^{a}$ & $0.27^{a}$ & $0.24^{a}$ \\
\hline & $(0.06)$ & $(0.08)$ & $(0.07)$ & $(0.09)$ & $(0.08)$ & $(0.07)$ \\
\hline \multirow[t]{2}{*}{ Share of U.S. MOFAs } & -0.54 & $-1.05^{a}$ & -0.48 & -0.30 & $-0.72^{b}$ & $-0.97^{a}$ \\
\hline & $(0.35)$ & $(0.34)$ & $(0.33)$ & $(0.35)$ & $(0.35)$ & $(0.34)$ \\
\hline \multirow[t]{2}{*}{ Share of U.S. MOFAs X South dummy } & 1.13 & $1.49^{b}$ & 0.57 & 0.86 & $1.21^{c}$ & $1.26^{c}$ \\
\hline & $(0.69)$ & $(0.67)$ & $(0.67)$ & $(0.68)$ & $(0.73)$ & $(0.67)$ \\
\hline Observations & 35,607 & 35,607 & 35,607 & 35,607 & 35,607 & 35,607 \\
\hline
\end{tabular}


fully deflate the positive impact of governance on NS-FDI and SS-FDI that we have found. Such a channel also cannot really explain why the latter tends to be less sensitive to governance than the former, since, if anything, it ought to be stronger for NS-FDI, given the larger absolute size of their outward FDI and the absence of reason to believe that S-MNEs accumulate experience at a faster rate than N-MNEs. Finally, while the potential existence of simultaneity is easy to discuss in the context of an unconditional impact of governance on FDI, it is much harder to cast in the context of the specific causal mechanism that we have put forward, which conditions the impact of a destination country's governance on the quality of the source country's governance. Hence, we are fairly certain that our results are not solely the product of reverse causality.

\subsection{The mitigating role of bilateral ties}

In this last part of the paper, we explore whether other factors may encourage MNEs to invest in risky countries with more confidence. Some MNEs may not have any multilateral resilience advantage because they have never had experience of dealing with major institutional deficiencies in their home country. However, they may still have some knowledge about how to overcome the institutional voids present in a given destination country, as a result of the existence of bilateral ties. In order to test this hypothesis, we interact destination governance with the inverse of geographic distance, the existence of a common language, the degree of religious similarity, the size of migrant stocks and the presence of a colonial relationship. We expect a bilateral tie to decrease the sensitivity of MNEs to destination governance, regardless of their experience of poor governance at home. Our results correspond to the estimation of equation (3) and are reported in Table 12.

Sharing a common language (panels B and G) appears to decrease the impact of destination governance on NS-FDI and SS-FDI FDI considerably, especially when the governance dimensions are Government Effectiveness and Regulatory Quality. It is likely that not knowing the domestic language amplifies the operating difficulties caused by excessive bureaucracy and red tape. Other 'promising' candidates, such as religious similarity (panel C) or colonial relationship (panel F) have the expected negative signs but their statistically significant effect mostly seem to stem from their correlation with sharing a common language (panel G). It should be noted that these results do not necessarily imply that all the positive impacts of a common language on FDI result from mitigating the effects of poor governance. For instance, while the impact is neutral for NS-FDI when the value of destination governance is zero, it remains large and statistically significant for SS-FDI. 
Table 12: The mitigating role of bilateral ties

\begin{tabular}{|c|c|c|c|c|c|c|}
\hline Governance & $\begin{array}{l}\text { VA } \\
(1) \\
\end{array}$ & $\begin{array}{l}\text { PS } \\
(2)\end{array}$ & $\begin{array}{l}\text { GE } \\
(3)\end{array}$ & $\begin{array}{l}\text { RQ } \\
(4)\end{array}$ & $\begin{array}{l}\text { RL } \\
(5)\end{array}$ & $\begin{array}{l}\mathrm{CC} \\
(6) \\
\end{array}$ \\
\hline & \multicolumn{6}{|c|}{ A: Geographic distance } \\
\hline S. governance X D. governance & $\begin{array}{l}0.25^{a} \\
(0.07)\end{array}$ & $\begin{array}{l}0.23^{a} \\
(0.08)\end{array}$ & $\begin{array}{l}0.45^{a} \\
(0.08)\end{array}$ & $\begin{array}{l}0.36^{a} \\
(0.10)\end{array}$ & $\begin{array}{l}0.33^{a} \\
(0.08)\end{array}$ & $\begin{array}{l}0.25^{a} \\
(0.08)\end{array}$ \\
\hline \multirow[t]{2}{*}{ (1/ln (Geographic distance)) X D. governance } & $\begin{array}{c}9.11 \\
(5.69)\end{array}$ & $\begin{array}{l}12.00^{b} \\
(5.72)\end{array}$ & $\begin{array}{l}10.60 \\
(6.48)\end{array}$ & $\begin{array}{c}9.35 \\
(5.99)\end{array}$ & $\begin{array}{c}7.04 \\
(5.97)\end{array}$ & $\begin{array}{c}2.64 \\
(6.30)\end{array}$ \\
\hline & \multicolumn{6}{|c|}{ B: Common language } \\
\hline S. governance X D. governance & $\begin{array}{c}0.17^{a} \\
(0.06)\end{array}$ & $\begin{array}{c}0.20^{b} \\
(0.08)\end{array}$ & $\begin{array}{l}0.33^{a} \\
(0.07)\end{array}$ & $\begin{array}{l}0.23^{b} \\
(0.09)\end{array}$ & $\begin{array}{l}0.25^{a} \\
(0.08)\end{array}$ & $\begin{array}{l}0.20^{a} \\
(0.08)\end{array}$ \\
\hline \multirow[t]{2}{*}{ Common language X D. governance } & $\begin{array}{l}-0.23^{c} \\
(0.14)\end{array}$ & $\begin{array}{l}0.24^{c} \\
(0.13)\end{array}$ & $\begin{array}{l}-0.47^{a} \\
(0.15)\end{array}$ & $\begin{array}{c}-0.62^{a} \\
(0.15)\end{array}$ & $\begin{array}{l}-0.23^{c} \\
(0.14)\end{array}$ & $\begin{array}{c}-0.23 \\
(0.16)\end{array}$ \\
\hline & \multicolumn{6}{|c|}{ C: Religious similarity } \\
\hline S. governance X D. governance & $\begin{array}{l}0.21^{a} \\
(0.06)\end{array}$ & $\begin{array}{c}0.14^{c} \\
(0.08)\end{array}$ & $\begin{array}{l}0.38^{a} \\
(0.07)\end{array}$ & $\begin{array}{l}0.23^{b} \\
(0.10)\end{array}$ & $\begin{array}{l}0.31^{a} \\
(0.08)\end{array}$ & $\begin{array}{l}0.22^{a} \\
(0.08)\end{array}$ \\
\hline \multirow[t]{2}{*}{ Religious similarity X D. governance } & $\begin{array}{c}0.16 \\
(0.21)\end{array}$ & $\begin{array}{l}-0.16 \\
(0.19)\end{array}$ & $\begin{array}{l}-0.21 \\
(0.27)\end{array}$ & $\begin{array}{c}-0.70^{a} \\
(0.24)\end{array}$ & $\begin{array}{c}0.26 \\
(0.26)\end{array}$ & $\begin{array}{l}-0.11 \\
(0.25)\end{array}$ \\
\hline & \multicolumn{6}{|c|}{ D: Number of migrants from $S$ in $D$} \\
\hline S. governance X D. governance & $\begin{array}{c}0.20^{a} \\
(0.06)\end{array}$ & $\begin{array}{c}0.19^{b} \\
(0.08)\end{array}$ & $\begin{array}{c}0.37^{a} \\
(0.07)\end{array}$ & $\begin{array}{l}0.31^{a} \\
(0.09)\end{array}$ & $\begin{array}{l}0.26^{a} \\
(0.08)\end{array}$ & $\begin{array}{l}0.23^{a} \\
(0.07)\end{array}$ \\
\hline \multirow[t]{2}{*}{$\ln$ (Migrants from $S$ in D) X D. governance } & $\begin{array}{l}-0.00 \\
(0.02)\end{array}$ & $\begin{array}{c}0.02 \\
(0.02)\end{array}$ & $\begin{array}{l}-0.03 \\
(0.02)\end{array}$ & $\begin{array}{l}-0.00 \\
(0.02)\end{array}$ & $\begin{array}{l}-0.02 \\
(0.02)\end{array}$ & $\begin{array}{c}-0.00 \\
(0.02)\end{array}$ \\
\hline & \multicolumn{6}{|c|}{ E: Number of migrants from $D$ in $S$} \\
\hline S. governance X D. governance & $\begin{array}{l}0.22^{a} \\
(0.06)\end{array}$ & $\begin{array}{c}0.15^{b} \\
(0.08)\end{array}$ & $\begin{array}{l}0.39^{a} \\
(0.07)\end{array}$ & $\begin{array}{l}0.30^{a} \\
(0.09)\end{array}$ & $\begin{array}{l}0.28^{a} \\
(0.07)\end{array}$ & $\begin{array}{l}0.23^{a} \\
(0.07)\end{array}$ \\
\hline \multirow[t]{2}{*}{$\ln$ (Migrants from D in S) X D. governance } & $\begin{array}{c}-0.05^{a} \\
(0.01)\end{array}$ & $\begin{array}{l}0.04^{b} \\
(0.02)\end{array}$ & $\begin{array}{c}0.01 \\
(0.02)\end{array}$ & $\begin{array}{c}0.03 \\
(0.02)\end{array}$ & $\begin{array}{c}0.02 \\
(0.02)\end{array}$ & $\begin{array}{c}0.02 \\
(0.02)\end{array}$ \\
\hline & \multicolumn{6}{|c|}{ F: Colonial relationship } \\
\hline S. governance X D. governance & $\begin{array}{l}0.20^{a} \\
(0.06)\end{array}$ & $\begin{array}{c}0.16^{b} \\
(0.08)\end{array}$ & $\begin{array}{l}0.40^{a} \\
(0.07)\end{array}$ & $\begin{array}{l}0.30^{a} \\
(0.09)\end{array}$ & $\begin{array}{l}0.29^{a} \\
(0.07)\end{array}$ & $\begin{array}{l}0.24^{a} \\
(0.07)\end{array}$ \\
\hline \multirow[t]{2}{*}{ Colonial relationship X D. governance } & $\begin{array}{l}-0.02 \\
(0.22)\end{array}$ & $\begin{array}{c}0.03 \\
(0.19)\end{array}$ & $\begin{array}{l}-0.53^{b} \\
(0.25)\end{array}$ & $\begin{array}{l}-0.78^{a} \\
(0.27)\end{array}$ & $\begin{array}{l}-0.21 \\
(0.26)\end{array}$ & $\begin{array}{l}-0.29 \\
(0.25)\end{array}$ \\
\hline & \multicolumn{6}{|c|}{ G: Promising ties } \\
\hline S. governance X D. governance & $\begin{array}{l}0.19^{a} \\
(0.06)\end{array}$ & $\begin{array}{l}0.19^{b} \\
(0.09)\end{array}$ & $\begin{array}{l}0.35^{a} \\
(0.07)\end{array}$ & $\begin{array}{l}0.20^{b} \\
(0.10)\end{array}$ & $\begin{array}{l}0.29^{a} \\
(0.08)\end{array}$ & $\begin{array}{l}0.21^{a} \\
(0.08)\end{array}$ \\
\hline Common language & $\begin{array}{c}0.22 \\
(0.18)\end{array}$ & $\begin{array}{l}0.50^{a} \\
(0.19)\end{array}$ & $\begin{array}{c}0.24 \\
(0.21)\end{array}$ & $\begin{array}{c}0.09 \\
(0.19)\end{array}$ & $\begin{array}{c}0.29 \\
(0.22)\end{array}$ & $\begin{array}{c}0.24 \\
(0.22)\end{array}$ \\
\hline Common language $\mathrm{X}$ South dummy & $\begin{array}{c}0.68^{b} \\
(0.27)\end{array}$ & $\begin{array}{l}0.90^{a} \\
(0.26)\end{array}$ & $\begin{array}{c}0.60^{b} \\
(0.28)\end{array}$ & $\begin{array}{l}0.85^{a} \\
(0.28)\end{array}$ & $\begin{array}{l}0.80^{a} \\
(0.29)\end{array}$ & $\begin{array}{l}0.78^{a} \\
(0.29)\end{array}$ \\
\hline Common language X D. governance & $\begin{array}{l}-0.30^{c} \\
(0.16)\end{array}$ & $\begin{array}{c}0.34^{b} \\
(0.15)\end{array}$ & $\begin{array}{l}-0.42^{b} \\
(0.17)\end{array}$ & $\begin{array}{l}-0.45^{b} \\
(0.18)\end{array}$ & $\begin{array}{c}-0.28^{c} \\
(0.16)\end{array}$ & $\begin{array}{c}-0.20 \\
(0.18)\end{array}$ \\
\hline Colonial relationship X D. governance & $\begin{array}{c}0.12 \\
(0.24)\end{array}$ & $\begin{array}{l}-0.13 \\
(0.21)\end{array}$ & $\begin{array}{l}-0.29 \\
(0.27)\end{array}$ & $\begin{array}{l}-0.47^{c} \\
(0.28)\end{array}$ & $\begin{array}{l}-0.11 \\
(0.27)\end{array}$ & $\begin{array}{l}-0.17 \\
(0.27)\end{array}$ \\
\hline Religious similarity X D. governance & $\begin{array}{c}0.32 \\
(0.24)\end{array}$ & $\begin{array}{l}-0.33 \\
(0.21)\end{array}$ & $\begin{array}{c}0.06 \\
(0.29)\end{array}$ & $\begin{array}{l}-0.40 \\
(0.28)\end{array}$ & $\begin{array}{c}0.43 \\
(0.28)\end{array}$ & $\begin{array}{c}0.03 \\
(0.27)\end{array}$ \\
\hline Observations & 46,332 & 46,332 & 46,332 & 46,332 & 46,332 & 46,332 \\
\hline
\end{tabular}

Notes: ${ }^{a} \mathrm{p}<0.01{ }^{b} \mathrm{p}<0.05^{c} \mathrm{p}<0.10$. Cluster-robust standard errors in parentheses. VA: Voice and Accountability; PS: Political Stability; GE: Government Effectiveness; RQ; Regulatory Quality; RL: Rule of Law; CC: Control of Corruption. S: Source; D: Destination. All regressions include the full set of explanatory variables that we have previously used (see equation (4)). Their coefficients are not reported to save space. 
We find no evidence that migrants help to overcome institutional barriers in the destination country, as the coefficients on the interaction terms involving migrant stocks are small and insignificant. Hence, migrant networks do not seem to provide MNEs with informal arrangements substituting to weak contract enforcement formal institutions.

The coefficient on the inverse of physical distance has an unexpected positive sign but is mostly insignificant. That suggests that physical proximity, and the possibility of inter-country traveling, does not give any insight in how to deal with the institutional deficiencies of the destination country. Finally, we still find strong supporting evidence for the generic resilience advantage, despite the additional interaction terms.

\section{Conclusion}

In this paper, we have used our systematic analysis of the determinants of SS-FDI and NS-FDI as a canvas to explore how MNEs location decisions are shaped by better acquaintance with a foreign market resulting from bilateral ties, experience of international expansion or knowledge of how to deal with poor governance. Our picture of S-MNEs is very much in line with anecdotal evidence and case studies. In contrast to N-MNEs, they tend to be attracted to physically and linguistically close countries, presumably because as a group they have not yet acquired enough international experience to deal with the challenges of investing in more distant countries. On the other hand, we demonstrate extensively that their behaviour is less influenced by macroeconomic and governance conditions than their Northern counterparts. We find robust evidence that this relative insensitivity stems from the successful application of the experiential knowledge that they have accumulated in their home country on how to deal with institutional voids. We also show that both NS-FDI and SS-FDI are influenced by bilateral ties and international institutions. More specifically, beyond confirming that physical proximity and a shared common language influences bilateral FDI, we also put forward the importance of religious similarity as a proxy for trust, the role of migrant networks -which appears to differ depending on their 'direction', and the positive impact of multilateral RTA on intra-regional SS-FDI and extra-regional NS-FDI. In addition, while only S-MNEs benefit from a multilateral resilience advantage, some of these bilateral ties confer a reduction in the information and transaction costs associated with entering and operating in a foreign business environment characterised by weak institutions to all MNEs. A common language appears to be particularly important. On the other hand, contrary to what has been sometimes hypothesised in the literature, migrant networks do not seem to alleviate the institutional constraints that a firm may face. Finally, it is important to stress that we do not argue that the FSAs of S-MNEs consist in only a resilience advantage. We see the latter as complementing and enabling their other FSAs, which, according to some tentative evidence, seem to have 
the potential to be as technologically advanced as those of N-MNEs.

\section{References}

Acemoglu, D., S. Johnson, J. Robinson, and Y. Thaicharoen, 2003, "Institutional causes, macroeconomic symptoms: volatility, crises and growth," Journal of Monetary Economics, 50(1), 49-123.

Aykut, D., and D. Ratha, 2004, “South-South FDI Flows: How Big Are They?," Transnational Corporations, 13(1), 149-176.

Azémar, C., and R. Desbordes, 2009, "Public Governance, Health and Foreign Direct Investment in Sub-Saharan Africa," Journal of African Economies, 18(4), 667-709.

Blomstrom, M., and A. Kokko, 1997, "Regional Integration and Foreign Direct Investment,” NBER Working Paper, $n^{\circ} 6019$.

Brewer, P. A., 2007, “Operationalizing Psychic Distance: A Revised Approach,” Journal of International Marketing, $15(1), 44-66$.

Buch, C. M., J. Kleinert, A. Lipponer, and F. Toubal, 2005, "Determinants and Effects of Foreign Direct Investment: Evidence Fromh German Firm-level Data,” Economic Policy, 20(41), 52-110.

Cuervo-Cazurra, A., 2006, “Who Cares About Corruption?,” Journal of International Business Studies, 37(6), 807-822.

Cuervo-Cazurra, A., and M. Genc, 2008, “Transforming Disadvantages into Advantages: Developing-Country MNEs in the Least Developed Countries,” Journal of International Business Studies, 39(6), 957-979.

Darby, J., R. Desbordes, and I. Wooton, 2010, "Does Public Governance Always Matter? How Experience of Poor Institutional Quality Influences FDI to the South,” CESifo Working Paper Series, n³290.

Daude, C., and E. Stein, 2007, “The Quality of Institutions and Foreign Direct Investment,” Economics and Politics, 19(3), 317-344.

Desbordes, R., 2007, “The Sensitivity of U.S. Multinational Enterprises to Political and Macroeconomic Uncertainty: A Sectoral Analysis," International Business Review, 16(6), 732-750. 
Dixit, A., 2009, “Governance Institutions and Economic Activity,” American Economic Review, 99(1), 5-24.

Egger, P., 2008, “On the role of distance for outward FDI,” The Annals of Regional Science, 42, 375-389.

Eriksson, K., J. Johanson, A. Majkgard, and D. D. Sharma, 1997, "Experiential Knowledge and Cost in the Internationalization Process," Journal of International Business Studies, 28(2), 337-360.

Fischer, S., 1993, “The Role of Macroeconomic Factors in Growth,” Journal of Monetary Economics, 32(3), 485-512.

Gao, T., 2005, “Foreign Direct Investment From Developing Asia: Some Distinctive Features,” Economics Letters, 86(1), $29-35$.

Giuliano, P., A. Spilimbergo, and G. Tonon, 2006, “Genetic, Cultural and Geographical Distances,” CEPR Discussion Papers, 5807.

Globerman, S., and D. Shapiro, 2002, "Global Foreign Direct Investment Flows: The Role of Governance Infrastructure," World Development, 30(11), 1899-1919.

Goldberg, M. A., R. L. Heinkel, and M. D. Levi, 2005, "Foreign direct investment: The human dimension," Journal of International Money and Finance, 24(6), 913-934.

Goldstein, A., 2009, Multinational Companies from Emerging Economies. Basingstoke: Palgrave Macmillan.

Guiso, L., P. Sapienza, and L. Zingales, 2009, “Cultural Biases in Economic Exchange?," The Quarterly Journal of Economics, 124(3), 1095-1131.

Head, K., T. Mayer, and J. Ries, 2010, “The Erosion of Colonial Trade Linkages After Independence,” Journal of International Economics, 81(1), 1-14.

Heston, A., R. Summers, and B. Aten, 2009, "Penn World Table Version 6.3," Center for International Comparisons at the University of Pennsylvania.

Hines, J. R. J., and E. M. Rice, 1994, “Fiscal Paradise: Foreign Tax Havens and American Business,” The Quarterly Journal of Economics, 109(1), 149-182.

Javorcik, B. S., a. Özden, M. Spatareanu, and C. Neagu, 2011, "Migrant networks and foreign direct investment,” Journal of Development Economics, 94(2), 231-241. 
Johanson, J., and J.-E. Vahlne, 1977, “The Internationalization Process of the Firm. A Model of Knowledge Development and Increasing Foreign Market Commitments,” Journal of International Business Studies, 8(1), 23-32.

Johanson, J., and F. Wiedersheim-Paul, 1975, “The Internalization of the the Firm — Four Swedish Cases," Journal of Management Studies, 12(3), 305-323.

Kaufmann, D., A. Kraay, and M. Mastruzzi, 2004, “Governance Matters III: Governance Indicators for 1996-2002,” World Bank Working Paper, $\mathrm{n}^{\circ} 3106$.

—_ 2008, “Governance Matters VII : Aggregate and Individual Governance Indicators 1996-2007,” World Bank Policy Research Working Paper, nº4654.

Khanna, T., and K. G. Palepu, 2010, Winning in Emerging Markets. Boston: Harvard Business Press.

Kumar, K., 1982, “Third World Multinationals: A Growing Force in International Relations,” International Studies Quarterly, 26(3), 397-424.

Lall, S., 1983, The New Multinationals. The Spread of Third World Enterprises. London: John Wiley \& Sons.

Lecraw, D. J., 1977, “Direct Investment by Firms from Less Developed Countries,” Oxford Economic Papers, 29(3), $442-57$.

Levy-Yeyati, E., U. Panizza, and E. Stein, 2007, “The Cyclical Nature of FDI Flows,” Journal of International Money and Finance, 26(1), 104-130.

Lipsey, R. E., 2007, “Defining and Measuring the Location of FDI Output,” NBER Working Paper, n 12996.

MacDermott, R., 2007, "Regional Trade Agreement and Foreign Direct Investment," The North American Journal of Economics and Finance, 18(1), 107-116.

Makino, S., and E. W. K. Tsang, 2011, “Historical ties and foreign direct investment: An exploratory study," Journal of International Business Studies, 42(4), 545-557.

Mataloni, R., and M. Fahim-Nader, 1996, “Operations of U.S. Multinational Companies: Preliminary Results from the 1994 Benchmark Survey," Survey of Current Business, December, 11-37.

Mayer, T., and S. Zignago, 2006, Notes on CEPII's Distances Measures. CEPII dataset.

McCleary, R. M., and R. J. Barro, 2006, “Religion and Economy,” Journal of Economic Perspectives, 20(2), 49-72. 
Neary, P. J., 2009, “Trade costs and foreign direct investment," International Review of Economics \& Finance, 18(2), $207-218$.

Noy, I., and T. B. Vu, 2007, “Capital Account Liberalization and Foreign Direct Investment,” The North American Journal of Economics and Finance, 18(2), 175-194.

Petroulas, P., 2007, “The effect of the euro on foreign direct investment," European Economic Review, 51(6), 1468-1491.

Portes, R., and H. Rey, 2005, “The determinants of cross-border equity flows,” Journal of International Economics, 65(2), 269-296.

Ramamurti, R., and J. V. Singh, 2009, Emerging Multinationals in Emerging Markets. Cambridge: Cambridge University Press.

Rauch, J. E., 2001, “Business and Social Networks in International Trade,” Journal of Economic Literature, 39(4), 11771203.

Santos, S., and S. Tenreyro, 2006, “The Log of Gravity,” The Review of Economics and Statistics, 88(4), 641-658.

Smarzynska, B., and S.-J. Wei, 2000, “Corruption and the Composition of Foreign Direct Investment: Firm-Level Evidence," World Bank Working Paper, n²360.

Spolaore, E., and R. Wacziarg, 2009, “The Diffusion of Development,” The Quarterly Journal of Economics, 124(2), 469-529.

Stein, E., and C. Daude, 2007, "Longitude matters: Time zones and the location of foreign direct investment," Journal of International Economics, 71(1).

Tong, S. Y., 2005, “Ethnic Networks in FDI and the Impact of Institutional Development,” Review of Development Economics, 9(4), 563-580.

UNCTAD, 2003, World Investment Report 2003: FDI Policies for Development: National and International Perspectives. New-York and Geneva: United Nations.

— , 2006, World Investment Report 2006: FDI from Developing and Transition Economies: Implications for Development. New-York and Geneva: United Nations. 
, 2010, World Investment Report 2010: Investing in a Low-Carbon Economy. New-York and Geneva: United Nations.

Van der Ploeg, F., 2011, “Natural Resources: Curse or Blessing?," Journal of Economic Literature, 49(2), 366-420.

Velde te, D. W., and D. Bezeme, 2006, "Regional Integration and Foreign Direct Investment in Developing Countries," Transnational Corporations, 15(2), 41-70.

Wei, S.-J., 2000, “How Taxing is Corruption on International Investors?,” The Review of Economics and Statistics, 82(1), $1-11$.

Wells, L. T. J., 1983, Third World Multinationals. London: The MIT Press.

— , 2009, “Third World Multinationals: A Look Back,” in Emerging Multinationals in Emerging Markets, ed. by R. Ramamurti, and J. V. Singh. Cambridge: Cambridge University Press.

Winkelmann, R., 2008, Econometric Analysis of Count Data. Berlin: Springer-Verlag Berlin Heidelberg.

Wooldridge, J. M., 2002, Introductory Econometrics. A Modern Approach. South-Western College Publishing.

Zaheer, S., 1995, “Overcoming the Liability of Foreignness,” Academy of Management Journal, 38(2), $341-363$. 
Appendix to

Market Familiarity and the Location of

South and North MNEs 


\section{Appendix}

Table 13: Summary statistics for NS-FDI

\begin{tabular}{|c|c|c|c|c|}
\hline Variable & Mean & Std. Dev. & Min. & Max. \\
\hline Number of distinct parents & 4.11 & 45.63 & 0 & 2985 \\
\hline Source $\ln (\mathrm{GDP})$ & 19.48 & 1.63 & 15.96 & 23.1 \\
\hline Destination $\ln (\mathrm{GDP})$ & 17.29 & 1.89 & 13.36 & 22.46 \\
\hline Source $\ln (\mathrm{GDPPC})$ & 10.27 & 0.27 & 9.84 & 10.97 \\
\hline Destination $\ln ($ GDPPC $)$ & 8.18 & 0.91 & 6.07 & 10.08 \\
\hline Destination average real GDPPC growth rate & 2.62 & 4.41 & -3.87 & 40.14 \\
\hline Source average real GDPPC growth rate & 2.42 & 1.39 & -0.68 & 6.22 \\
\hline Source $\ln$ (inflation) & 0.73 & 0.50 & -0.49 & 2 \\
\hline Destination $\ln$ (inflation) & 2.06 & 1.03 & -0.59 & 6.41 \\
\hline $\ln$ (geographical distance) & 8.80 & 0.62 & 5.19 & 9.89 \\
\hline Contiguity dummy & 0 & 0.07 & 0 & 1 \\
\hline Time zone difference & 4.34 & 3.29 & 0 & 12 \\
\hline Destination country landlocked & 0.27 & 0.44 & 0 & 1 \\
\hline Bilateral RTA (BRTA) & 0.01 & 0.11 & 0 & 1 \\
\hline BRTA with D. in Multilateral RTA (MRTA) & 0.01 & 0.06 & 0 & 0.78 \\
\hline MRTA & 0 & 0.05 & 0 & 1 \\
\hline D. in MRTA & 0.62 & 0.44 & 0 & 1 \\
\hline Currency union dummy & 0 & 0 & 0 & 0 \\
\hline Common language dummy & 0.12 & 0.32 & 0 & 1 \\
\hline Religious similarity & 0.14 & 0.20 & 0 & 0.86 \\
\hline $\ln$ (genetic distance) & 6.73 & 0.84 & 1.26 & 8.02 \\
\hline $\ln ($ number of migrants from $S$. in D.) & 2.89 & 2.8 & 0 & 12.77 \\
\hline $\ln ($ number of migrants from $\mathrm{D}$. in $\mathrm{S}$.) & 4.84 & 3.52 & 0 & 16.05 \\
\hline Colonial relationship dummy & 0.03 & 0.17 & 0 & 1 \\
\hline Source voice and accountability & 1.01 & 0.75 & -0.90 & 1.63 \\
\hline Destination voice and accountability & -0.47 & 0.71 & -1.82 & 1.08 \\
\hline Source political stability & 0.92 & 0.52 & -1.19 & 1.49 \\
\hline Destination political stability & -0.45 & 0.75 & -2.23 & 0.98 \\
\hline Source government effectiveness & 1.49 & 0.58 & 0.20 & 2.13 \\
\hline Destination government effectiveness & -0.47 & 0.56 & -1.64 & 1.19 \\
\hline Source regulatory quality & 1.21 & 0.40 & 0.21 & 1.76 \\
\hline Destination regulatory quality & -0.43 & 0.64 & -2.09 & 1.39 \\
\hline Source rule of law & 1.38 & 0.46 & 0.52 & 1.94 \\
\hline Destination rule of law & -0.53 & 0.60 & -1.73 & 1.22 \\
\hline Source control of corruption & 1.51 & 0.63 & 0.36 & 2.35 \\
\hline Destination control of corruption & -0.50 & 0.57 & -1.7 & 1.36 \\
\hline Observations & \multicolumn{4}{|c|}{8748} \\
\hline
\end{tabular}

S: Source; D: Destination. 
Table 14: Summary statistics for SS-FDI

\begin{tabular}{|c|c|c|c|c|}
\hline Variable & Mean & Std. Dev. & Min. & Max. \\
\hline Number of distinct parents & 0.07 & 2.04 & 0 & 339 \\
\hline Source $\ln (\mathrm{GDP})$ & 17.32 & 1.86 & 13.36 & 22.46 \\
\hline Destination $\ln (\mathrm{GDP})$ & 17.29 & 1.89 & 13.36 & 22.46 \\
\hline Source $\ln (\mathrm{GDPPC})$ & 8.24 & 0.93 & 6.07 & 10.08 \\
\hline Destination $\ln ($ GDPPC) & 8.18 & 0.91 & 6.07 & 10.08 \\
\hline Destination average real GDPPC growth rate & 2.62 & 4.41 & -3.87 & 40.14 \\
\hline Source average real GDPPC growth rate & 2.73 & 4.31 & -3.87 & 40.14 \\
\hline Source $\ln$ (inflation) & 2.06 & 1.04 & -0.59 & 6.41 \\
\hline Destination $\ln$ (inflation) & 2.06 & 1.03 & -0.59 & 6.41 \\
\hline $\ln$ (geographical distance) & 8.76 & 0.73 & 5.09 & 9.88 \\
\hline Contiguity dummy & 0.03 & 0.16 & 0 & 1 \\
\hline Time zone difference & 4.49 & 3.27 & 0 & 12 \\
\hline Destination country landlocked & 0.27 & 0.44 & 0 & 1 \\
\hline Bilateral RTA (BRTA) & 0 & 0.01 & 0 & 0.78 \\
\hline BRTA with D. in Multilateral RTA (MRTA) & 0 & 0.02 & 0 & 1 \\
\hline MRTA & 0.04 & 0.19 & 0 & 1 \\
\hline D. in MRTA & 0.59 & 0.45 & 0 & 1 \\
\hline Currency union dummy & 0.02 & 0.12 & 0 & 1 \\
\hline Common language dummy & 0.12 & 0.32 & 0 & 1 \\
\hline Religious similarity & 0.17 & 0.23 & 0 & 0.98 \\
\hline $\ln ($ genetic distance $)$ & 6.83 & 1.04 & 0 & 8.17 \\
\hline $\ln ($ number of migrants from $S$. in D.) & 1.94 & 2.73 & 0 & 15.15 \\
\hline $\ln ($ number of migrants from D. in S.) & 1.96 & 2.74 & 0 & 15.15 \\
\hline Colonial relationship dummy & 0 & 0.06 & 0 & 1 \\
\hline Source voice and accountability & -0.39 & 0.77 & -1.82 & 1.15 \\
\hline Destination voice and accountability & -0.47 & 0.71 & -1.82 & 1.08 \\
\hline Source political stability & -0.38 & 0.77 & -2.23 & 0.98 \\
\hline Destination political stability & -0.45 & 0.75 & -2.23 & 0.98 \\
\hline Source government effectiveness & -0.40 & 0.60 & -1.64 & 1.19 \\
\hline Destination government effectiveness & -0.47 & 0.56 & -1.64 & 1.19 \\
\hline Source regulatory quality & -0.35 & 0.70 & -2.09 & 1.39 \\
\hline Destination regulatory quality & -0.43 & 0.64 & -2.09 & 1.39 \\
\hline Source rule of law & -0.46 & 0.63 & -1.73 & 1.22 \\
\hline Destination rule of law & -0.53 & 0.60 & -1.73 & 1.22 \\
\hline Source control of corruption & -0.44 & 0.59 & -1.7 & 1.36 \\
\hline Destination control of corruption & -0.50 & 0.57 & -1.70 & 1.36 \\
\hline Observations & \multicolumn{4}{|c|}{3758} \\
\hline
\end{tabular}

S: Source; D: Destination. 
Table 15: Destination and source countries in the sample

\begin{tabular}{|c|c|c|c|}
\hline Afghanistan & Djibouti & Kyrgyzstan & Rwanda \\
\hline Albania & Dominican Republic & Laos & Saudi Arabia \\
\hline Algeria & Ecuador & Latvia* & Senegal \\
\hline Angola & Egypt & Lesotho & Seychelles \\
\hline Argentina & El Salvador & Libya & Sierra Leone \\
\hline Armenia & Equatorial Guinea & Lithuania* & Slovakia* \\
\hline Australia* & Eritrea* & Madagascar & Slovenia* \\
\hline Austria* & Estonia* & Malawi & Solomon Islands \\
\hline Azerbaijan & Ethiopia & Malaysia & South Africa \\
\hline Bangladesh & Fiji & Mali & Spain* \\
\hline Belarus & Finland* & Mauritania & Sri Lanka \\
\hline Belgium* & France* & Mauritius & Sudan \\
\hline Benin & Gabon & Mexico & Suriname \\
\hline Bhutan & Gambia & Mongolia & Swaziland \\
\hline Bolivia & Georgia & Morocco & Sweden* \\
\hline Botswana & Germany* & Mozambique & Syria \\
\hline Brazil & Ghana & Namibia & Taiwan* \\
\hline Brunei Darussalam* & Greece* & Nepal & Tajikistan \\
\hline Bulgaria* & Guatemala & Netherlands* & Thailand \\
\hline Burkina Faso & Guinea & New Zealand* & Togo \\
\hline Burundi & Guinea-Bissau & Nicaragua & Tonga \\
\hline Cameroon & Guyana & Niger & Trinidad and Tobago \\
\hline Canada* & Haiti & Nigeria & Tunisia \\
\hline Cape Verde & Honduras & Norway* & Turkey \\
\hline Central African Republic & Hungary* & Oman & Turkmenistan \\
\hline Chad & Iceland* & Pakistan & Uganda \\
\hline Chile & India & Papua New Guinea & Ukraine \\
\hline China & Indonesia & Paraguay & United Arab Emirates* \\
\hline Colombia & Iran & Peru & United Kingdom* \\
\hline Comoros & Israel* $^{*}$ & Philippines & United Republic of Tanzania \\
\hline Congo & Italy* $^{*}$ & Poland* & United States* \\
\hline Costa Rica & Jamaica & Portugal $^{*}$ & Uruguay \\
\hline Cote d'Ivoire & Japan* & Qatar* & Uzbekistan \\
\hline Croatia & Kazakhstan & Republic of Korea & Venezuela \\
\hline Czech Republic* & Kenya & Republic of Moldova & Viet Nam \\
\hline Denmark* & Kuwait* & Russian Federation & Zambia \\
\hline
\end{tabular}

\footnotetext{
*: Source countries only
} 